九州大学学術情報リポジトリ

Kyushu University Institutional Repository

\title{
Assessment of Predominant Microstructural Features Controlling 3D Short Crack Growth Behavior via a Surrogate Approach in Ti-6AL-4V
}

Hassanipour, M.

Department of Mechanical Engineering, Kyushu University

Watanabe, Satoshi

Department of Mechanical Engineering, Kyushu University

Hirayama, Kyosuke

Department of Mechanical Engineering, Kyushu University

$\mathrm{Li}, \mathrm{H}$.

Department of Mechanical Engineering, Kyushu University

他

http://hdl. handle. net/2324/4150458

出版情報: Materials Science and Engineering：A. 751，pp.351-362，2019-03-28. Elsevier バージョン：

権利関係 : 


\section{Title:}

Assessment of Predominant Microstructural Features Controlling 3D

Short Crack Growth Behavior via a Surrogate Approach in Ti-6Al-4V

\section{Authors:}

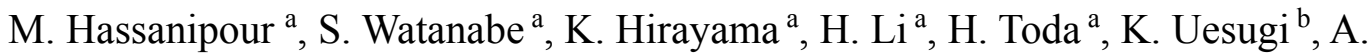

Takeuchi ${ }^{\mathrm{b}}$

\section{Affiliations:}

${ }^{a}$ Department of Mechanical Engineering, Kyushu University, 744, Motooka, Nishi Ward, Fukuoka, Fukuoka 819-0395, Japan

b Japan Synchrotron Radiation Research Institute, 1-1-1, Kouto, Sayo Cho, Sayo Gun, Hyogo 679-5148, Japan

\section{Corresponding Author:}

M. Hassanipour

Email: meysam.hp1@gmail.com

Phone: +81-92-802-3215 


\section{Abstract}

Complex 3D microstructure and mechanical properties can be precisely characterized and linked by employing the X-ray micro-tomography combined with EBSD serial sectioning. Global sensitivity and principal component analysis can be used to rank and coarsen the contributing features that control the mechanical response. Afterwards, by creating surrogate models, the relationship between the most contributing features and mechanical properties can be further analyzed via support vector machines. The aforementioned novel approach was applied to study the relationship between microstructural features and short crack behavior in a Ti-6Al-4V alloy. It was revealed that short crack path, growth rate, and its variation are mainly affected by the interaction with neighboring grains; however, as the short crack front becomes larger, there is a decrease and a change in the importance of those interactions. A high number of grains in contact with a long cracked $\alpha$ grain in the loading direction may impose a constraint on the crack opening resulting in low crack growth rates. As the crack length increases, the increase in the shear stress field away from the cracked grain leads to crack bifurcations and the formation of secondary cracks, resulting in a decrease in crack driving forces with low crack growth rates. It was concluded that short crack behavior is strongly affected by the shape, size, and crystallographic features of its neighboring grains, which cause variation in the shear and tensile stress fields resulting in crack growth rate variation.

Keywords: X-ray microtomography, Short crack propagation, 3D microstructure, Global sensitivity analysis, Principal component analysis, Surrogate model, Ti-6Al-4V 


\section{Introduction}

A detailed understanding of the mechanical properties in polycrystalline alloys, such as Ti-6Al-4V, requires a realistic investigation of microstructural features [1]. In the case of fatigue properties, as the cyclic loads are applied, small existing defects start to propagate on the surface and inside the microstructure [2]. Short crack propagates along the persistent slip bands inside a grain until it approaches the grain or phase boundary $[3,4]$. The crack growth rate decreases at the grain boundary and its subsequent path and growth depend on the size, crystallographic orientation, strength, etc., of the subsequent cracked grain [5-7]. For instance, studies have shown that a change in crack plane angle across the grain boundary can lead to crack growth rate variation $[8,9]$. As the short crack length and its plastic zones increase, it becomes less sensitive to the above-mentioned local microstructural features, which results in lower crack growth rate variation $[10,11]$.

Traditionally, the complex 3D microstructural features, e.g., grain size, have been characterized by averaging them on 2D cross-sections through the thickness $[12,13]$. On the other hand, 3D short crack growth has been simplified by measuring it on the $2 \mathrm{D}$ surface $[2,14]$. Finally, a correlation between the averaged microstructural features and short crack growth behavior has been estimated [15-18]. Using the traditional approach, a scatter band of short crack growth rate is estimated without considering the crack insitu interaction with various local 3D microstructural features [19,20].

Regarding the 3D analysis, quantitative tilt fractography combined with EBSD analysis has been used to study the effect of local 3D microstructural features on the short crack growth behavior [16,21]. For instance, it was shown that a cluster of $\alpha$ grains with relatively high Schmid factor and similar orientations leads to crack formation followed 
by propagation that causes fracture [22-25]. However, the post-fracture analysis is destructive and cannot capture the accurate in-situ 3D crack growth behavior in the local microstructure.

As a consequence, recent studies have employed X-ray synchrotron tomography in order to reach a non-destructive and in-situ observation of short crack growth behavior [26,27]. In addition, the diffraction contrast tomography has been employed to characterize the accurate 3D microstructural features [28,29]. However, the effect of 3D microstructure on the short crack growth are still qualitative [30,31]. On the other hand, advances have been made on short crack characterization by using finite element models considering fatigue indicator parameters [32-34]. However, there is major challenge to predict the accurate stress and strain due to different competing microstructural features $[34,35]$. As a result, there is an essential need for 3D experimental based methods that can extract the predominant microstructural features that control the $3 \mathrm{D}$ short crack growth behavior.

In this study, by employing the X-ray micro-tomography combined with EBSD serial sectioning, an explicit spatial and temporal linkage between 3D microstructural features and short crack behavior at low cycle fatigue in a Ti-6Al-4V alloy was established. Nonetheless, the interpretation of short crack behavior due to its interaction with large number of microstructural features is complicated. To overcome this issue, a surrogate approach via a set of advanced statistical techniques was applied. First, the global sensitivity analysis [36] was used to rank the contribution of the features to the short crack growth behavior. The principal component analysis [37] was performed to eliminate features with similar covariance but lower rankings. Afterwards, by creating surrogate models, the relationship between the most contributing microstructural features 
and short crack growth behavior were further analyzed using support vector machines [38].This procedure aids in revealing the possible microstructural mechanisms that control the short crack growth behavior. The above-mentioned approach can be applied to study the relationship between mechanical properties (fatigue, fracture, etc.) and the predominant 3D microstructural features in a wide range of polycrystalline alloys.

\section{Experimental procedures and surrogate approach}

\subsection{Material, fatigue testing, 3D reconstruction of microstructure and short crack}

The chemical composition and heat treatment of the Ti-6Al-4V alloy employed in this study is given in [9]. At the end of the heat treatment, this alloy was composed of $65 \%$ hexagonal close-packed (hcp) primary $\alpha$ phase and 35\% of acicular secondary $\alpha$ phase within the body center cubic (bcc) $\beta$ phase ( $\alpha+\beta$ phase).

As mentioned, the aim of this study was to characterize the short crack growth rate in the low cycle fatigue regime. A notch (existing defect) with a dimension of $60 \times 20 \times 4 \mu \mathrm{m}$ was made on the specimen with cross sections of $600 \times 600 \mu \mathrm{m}$ using a focused ion beam. Preliminary fatigue tests were conducted with different stress levels at $\mathrm{R}=0.1$ and 15 Hz. At a maximum stress of $778 \mathrm{MPa}$, the average fatigue lifetime of specimens was 30000 cycles, which corresponds to the low cycle fatigue regime.

As a result, the aforementioned load conditions were applied to monitor the growing crack inside the specimens using in situ computed tomography (CT) at the BL20XU beamline of SPring- 8 . The monochromatic X-ray energy of $30 \mathrm{keV}$ was produced by a liquid nitrogen-cooled Si (111) double crystal monochromator. During 180 degrees of stage rotation with 0.1 degree steps, 1800 scans were performed with an exposure time 
of $400 \mathrm{~ms}$. Other details of the scanning conditions can be found in [9].

Since the average size of the primary $\alpha$ grain was equal to $20 \mu \mathrm{m}$, the crack was periodically scanned for every $5 \mu \mathrm{m}$ of crack growth projection on the detector to characterize the crack growth inside the grains. The short crack growth was scanned for two different crack length regions. The applied maximum stress induces a monotonic plastic zone of $20 \mu \mathrm{m}$ ahead of the notch [39]; thus, it was ensured that the characterized crack front regions are outside of the induced plastic zone. The first region corresponds to 105 to $156 \mu \mathrm{m}$ (8700 to 10600 cycles, respectively) and the second region corresponds to 292 to $342 \mu \mathrm{m}$ (17000 to 18560 cycles, respectively). As the short crack front grows into the second region, a possible change in the interaction with different microstructural features can be analyzed.

The scanned absorption contrast images were converted into the phase contrast images in order to increase the contrast of gray values between $\alpha$ and $\alpha+\beta$ phases which enables to binarize them as shown in Figure 1. The $\alpha$ grains, their boundaries, and crystallographic orientations were determined and carefully verified by using the EBSD serial sectioning through the specimen thickness for every $3 \mu \mathrm{m}$. In total, $318 \alpha$ grains with their surrounding $\alpha+\beta$ phase were identified in the microstructure.

The absorption contrast images were used to determine the crack front coordinates for each image slice as compared to the notch; details can be found in [9]. The absorption images were aligned with the reconstructed $\alpha$ grains and their boundaries, which enables the identification of crack front coordinates in each grain. Overall, the crack front was growing inside 15 and $38 \alpha$ grains (cracked grains) in the first and second region, respectively. 


\subsection{Quantification of microstructural features and short crack behavior}

\subsubsection{Geometrical and crystallographic features of grains}

In order to investigate the effect of 3D microstructure on short crack growth behavior, a precise analysis of geometrical and crystallographic features of each cracked grain and its neighboring grains were carried out. To do so, the slice images of each grain were registered to define its centroid and to quantify its size, which is described as surface area, volume, and shape using the procedure introduced in [40]. The mass was assumed to be homogenously distributed in the grains and phases, so the centroid and the center of gravity of grains were identical. The shape of each grain was precisely quantified by ten features ( $F 1$ to $F 10)$ as described in Table 1 . The EBSD was employed to quantify the crystallographic orientations with respect to the macroscopic stress that results in the apparent Schmid factor on each crystallographic plane (basal, prismatic, pyramidal), and the maximum apparent Schmid factor for each grain. For the sake of brevity, the term Schmid factor is adopted hereafter.

\subsubsection{Multi-grain interactions}

The interaction of the neighboring or surrounding microstructure with the cracked grain can have a major effect on the crack growth behavior [16,22]. Therefore, in this section, the surrounding microstructure of the cracked grains was quantified in detail. The surrounding $\alpha$ grains were classified as grains in contact, in plastic zones and at the crack front to compare their microstructural features with the cracked grain (second row in Table 2). The type of microstructural features were defined as distribution, size, and crystallographic (first column in Table 2).

The cracked grains slice images were outlined to identify the contact area with the 
surrounding microstructure. The ratio between the contact area of $\alpha+\beta$ phase and $\alpha$ grains is defined as the percentage of surrounding $\alpha+\beta$ phase. On the other hand, the maximum and average values of each type of feature for $\alpha$ grains in contact were compared to the cracked grain (third column in Table 2). For instance, the ratio of the average volume of grains in contact $\left(V_{i c}^{A v e}\right)$ as compared to the cracked grain volume ( $V$ ) was quantified as $R V_{i c}^{A v e}$. This was also quantified for other types of features such as surface area $\left(R A{ }_{i c}^{A v e}\right)$, apparent Schmid factors $\left(R S_{i c}^{A v e}\right)$ and disorientations $\left(D O_{i c}{ }^{A v e}\right)$. The subscript shows the class of the feature (ic for grains in contact) and it implies that there is an interaction with the surrounding grains. The superscripts (Ave and $M a x$ ) show that the interaction involves the average and a maximum feature value, respectively.

As the crack front grows, there is an increase in the cyclic and monotonic plastic zones ahead of the crack front. The grains enclosed within these regions can also affect the crack path and growth behavior. As a result, the monotonic plastic zone size was calculated according to [41] along the inhomogeneous crack front inside each cracked grain. The cyclic plastic zone size was considered to be one-fourth of the monotonic plastic zone size [42]. The surrounding grains within those zones were classified as grains in plastic zones. For example, the ratio of the average basal Schmid factor of grains in the monotonic plastic zone $\left(B S_{m p}{ }^{A v e}\right)$ as compared to the cracked grain basal Schmid factor $(B S)$ was quantified as $R B S_{m p}{ }^{A v e}$. It should be stated that due to the experimental constraints such as holding time during the scanning, which can induce cold creep in titanium alloys, the local strain states could not be measured via synchrotron X-ray diffraction technique. As a consequence, the above-mentioned calculations of the plastic zones were assumed to be valid for the present short crack. 
The grains around the crack front can affect crack path and growth behavior. Thus, those grains were defined with respect to the crack wake and front geometry. The surrounding grains in contact within the height of the crack wake and within \pm 45 degrees deviation from the cracked grain gravity center were classified as grains at the crack front. For instance, the average orientation of grains at the crack front $\left(O_{c f}^{A v e}\right)$ as compared to the cracked grain $(O)$ was quantified as the disorientation between them $\left(D O_{c f}{ }^{A v e}\right)$.

\subsubsection{Short crack growth behavior at the sub-grain scale}

After quantifying the microstructural features of cracked grains and its surrounding microstructure, the short crack growth behavior in each cracked grain was analyzed. The average grain size is $20 \mu \mathrm{m}$ in this alloy; in consequence, crack growth was monitored for every $5 \mu \mathrm{m}$ using the X-ray micro-tomography to analyze crack growth inside the grains. This procedure has led to an average of four crack growth steps in each grain, which enabled us to define an average crack growth rate (ACGR) and standard deviation (CGSD) for each grain. On the other hand, the crack front coordinates that corresponded to the first and last cycles inside each grain were determined. From those coordinates, two vectors were defined to calculate the crack plane normal in each grain. By using the crack plane and the crystallographic grain orientation, i.e., Euler angles, the crack plane with respect to each grain's crystallographic plane was determined. The crack planes were classified as on the basal planes or on the non-basal planes. The fracture paths were classified as facet-like or non-facet-like path in grains. Thus, the short crack behavior consisted of crack path, growth rate and its variation. These parameters were quantified in 15 cracked grain, as the crack front became larger, 38 grains were cracked in the second region. 


\subsubsection{Normalization procedure}

The previous procedures resulted in a precise quantification of microstructural features and short crack growth behavior for 53 cracked grains. The microstructural features such as size, shape, distribution, and crystallographic have different distributions and units. For instance, grain volumes of cracked grains ranged from 896 to $35573 \mu \mathrm{m}^{3}$, but the average disorientations with the neighboring grains were between 0 to 90 degrees. In order to ensure that all features ranged from 0 to 1 , the normalization procedure was carried out. The distribution of each feature was binned and a particular case of the Gumbel probability density function considering the extreme distribution [43] was fitted to determine the maximum and minimum of each feature, so all features were scaled from 0 to 1 . For instance, the fitted curve for a feature (disorientation of grains in contact with the cracked grain) is given in Figure 2(a). To assess the relationship between the features and crack growth behavior, the short crack growth rate and its variation were also normalized using the same procedure (Figure 2(b)).

\subsection{Assessment of microstructure and short crack behavior relationship}

\subsubsection{Global sensitivity analysis}

A precise quantification of features and short crack growth was conducted and an explicit linkage was established. The matrix of the quantified microstructural features and short crack behavior along the crack front can be summarized in Figure 3. Nonetheless, the assessment of the complex relationship between $3 \mathrm{D}$ microstructural features and short crack behavior remains a major challenge. The global sensitivity analysis has been used to gain more knowledge about the complex behavior of a model [44]. In this analysis, the correlation between the inputs and the outputs are evaluated over a large region of space $[44,45]$. In the context of this study, the aforementioned 
analysis was applied to rank the 3D features (inputs) based on their correlation with the 3D short crack growth behavior (outputs) $[45,46]$.

In order to measure the correlation between the microstructural features and short crack behavior, the Pearson correlation coefficient (PCC) was employed [47,48]. This coefficient for each quantified microstructural feature and short crack growth behavior can be given by:

$\mathrm{PCC}=\operatorname{COV}($ microstructural feature, short crack behavior $) /(S D$ (microstructural feature) $\times S D$ (short crack behavior)).

The $C O V$ is the covariance between a quantified feature, such as the grain volume of a cracked grain, and short crack behavior, such as growth rate; $S D$ represents the standard deviation for the features and short crack behavior. An absolute PCC value equal to 1 shows a strong correlation, and 0 implies that there is no correlation. The microstructural features were ranked based on their correlation coefficients.

\subsubsection{Principal component analysis}

In order to evaluate the covariance between the ranked microstructural features, the principal component analysis (PCA) was used [37]. In this analysis, the features can be grouped into a new orientation with two principal component axes that are orthogonal. The first and second components are the axes with first and second largest variance, respectively. Each feature has a coordinate with a corresponding eigenvector. A close angle between the eigenvectors of the features shows that they have similar covariance, therefore leading to a similar effect on the crack growth behavior. An eigenvector angle of 5 degrees between microstructural features was determined to eliminate (hereafter,

called coarsen) features with similar covariance but lower ranking. Finally, three 
coarsened features that had the highest correlation with the short crack growth behavior were determined.

\subsubsection{Surrogate models via support vector machines}

The complex microstructural features were ranked and coarsened. The three highest ranked (most contributing) microstructural features controlling the short crack growth were selected for further analysis. By creating surrogate models, the relationship between those features and the short crack growth behavior were assessed via support vector machines [49]. Support vector machines (SVMs) are statistical learning machines that use a set of training and testing data (input-output pairs) to find an optimum classification or regression $[50,51]$.

In the case of the crack path, an optimum hyperplane can classify the features into those that lead to growth on the basal and non-basal planes. To do so, a classification type of support vector machines, known as the SVMC, was used [52,53]. An optimum kernel function and penalty parameter, $\mathrm{C}$, were defined by using grid search with crossvalidation that minimizes the training error [54,55]. A similar approach was used for a crack path in a facet-like and non-facet like path.

In the case of crack growth, the two most contributing microstructural features with respect to crack growth and its variation were considered for analysis. In this case, a type of support vector machines for regression, known as epsilon-SVR was applied [52,56]. The choice for the kernel and the epsilon was defined by using a grid search with crossvalidation. A three dimensional response surface curve was employed in order to visualize the trend in those features resulting in the lowest average crack growth rate and its variation. 


\section{Results}

\subsection{Short crack path and growth}

The three dimensional crack front and $\alpha$ grains projection on the xy plane are shown in Figure 4(a) and (b), respectively. Each line corresponds to an interrupted load cycle that results into a $5 \mu \mathrm{m}$ growth. The short crack has a highly inhomogeneous growth due to the interaction with the microstructural features. However, as it grows into the second region, the crack becomes close to a semi-elliptical crack with inhomogeneous growth at some locations.

Figure 5 shows the reconstructed cracked grain (blue grain) with its surrounding microstructure consisting of $\alpha+\beta$ phase and $\alpha$ grains. The corresponding superimposed crack images from 9250 to 9710 cycles in the blue grain show that the crack has a high average crack growth rate with low spatial variation. In the following section, the microstructural features that control the short crack path, growth rate, and its variation are analyzed. Those features are examined and quantified in 53 cracked grains in the first and in the second region of the crack front.

\subsection{Correlation between microstructural features and short crack behavior}

The results of principal component analysis (PCA) for the microstructural features are summarized in Figure 6. The explained variance by the two components is $50 \%$ and the clusters of features with common variance are given. It can be seen that a cluster of encircled features, such as the surface area of the cracked grain $(A)$, its volume $(V)$, and its integral of mean curvature $(M C)$ have similar angles in Figure 6. This implies that these features have similar covariance leading to a similar effect on crack growth behavior, so they are coarsened to the feature that has the highest correlation coefficient with the crack growth behavior. 
After coarsening the microstructural features using the PCA, three features having the highest Pearson correlation coefficient (PCC) values with respect to the crack path on the basal plane and in a facet-like fracture are shown in Figure 7(a). The crystallographic features of the surrounding grains have moderate to high correlation coefficients $[48,57]$ with the crack path (see written features with subscripts on bars in Figure 7(a)) in both regions. Thus, it can be said that the short crack, which grows from the first region into the second region in this alloy, is still sensitive to the microstructural features, so hereafter is referred to as the longer short crack.

In the first region, there is a strong correlation between the two crystallographic features (PCC values higher than 0.6) [57] and the crack growth on the basal plane and in a facetlike fracture. The crystallographic features leading to crack growth on the basal plane and in a facet-like fracture are similar. The basal Schmid factors of grains in the cyclic plastic zone ( $c p$ subscript) are the main class of features controlling the crack path (Figure 7(b)). The average and maximum basal Schmid factor of those grains $\left(R B S_{c p}{ }^{A v e}\right.$ and $R B S_{c p}{ }^{M a x}$, respectively), followed by the basal Schmid factor of the cracked grain $(B S)$ lead to a growth on the basal plane. In the case of facet-like growth, similar cyclic behavior plus the maximum basal Schmid factor of grain in contact $\left(R B S_{i c}{ }^{M a x}\right)$ are the most contributing features.

Regarding the longer short crack in the second region, there is a decrease in PCC values (see Figure 7(a) in the second region). The interaction with surrounding grains extends to the grains in contact, the crack font, and the monotonic plastic zone (subscripts with $i c, c f$ and, $m p$, respectively). In addition, the average disorientation of those grains and the maximum prismatic Schmid factor affect the crack path. This shows that the crack path selection is still affected by the crystallographic features of the surrounding grains 
for a longer short crack in this alloy (Figure 7(c)).

Regarding the microstructural features controlling the short crack growth rate and its variation (ACGR and CGSD, respectively), three coarsened features having the highest PCC values for each region are shown in Figure 8(a). The types of features include the distribution of phases $(\alpha$ and $\alpha+\beta)$, shape, size, and crystallographic features of the cracked $\alpha$ grains as compared to the surrounding $\alpha$ grains. Among those features, cracked grains shape and the relative crystallographic features of the neighboring grains are the most important features affecting crack growth behavior.

In the first region, the ACGR depends on the cracked grain shape ( $F 2$ and $F 10$ ), and the number of grains in contact with it ( $n_{\text {ic }}$ in Figure $\left.8(b)\right)$. Therefore, a combination of the cracked grain shape with the number of its surrounding grains can lead to a low crack growth rate. Similar to the crack path, the CGSD is controlled by grains crystallographic features in the cyclic plastic zone; in addition, the number of grain $\left(n_{\mathrm{cp}}\right)$ in the plastic zone contributes to the crack growth rates variation.

As the short crack front becomes larger in the second region, there is a decrease in PCC values of microstructural features (see Figure $8(\mathrm{a})$ in the second region). This is consistent with previous studies that have reported that longer crack lengths are less sensitive to the microstructural features $[58,59]$. In addition, it can be seen that there is a change and an overall decrease in the number of features that includes the strong interaction with surrounding grains as compared to the first region. The coarsened features still include the shape of the cracked grain and the surrounding grains in contact with it (Figure 8(c)); however, the crack growth behavior is affected by the higher number of grains features enclosed in the monotonic plastic zone (subscripts $m p$ ), which is similar to the microstructural features affecting the crack path. A combination of grain shape 
$(F 1)$ with its Schmid factor $(S)$ as compared to the Schmid factor of the surrounding grains $\left(R S_{m p}^{A v e}\right)$ may lead to a low crack growth rate. The cracked grain shape $(F 1$ and $F 2)$ in contact with a grain having a high surface area $\left(R A_{i c}{ }^{M a x}\right)$ may lead to low crack growth rate variation. It has been reported that a low disorientation between surrounding grains may lead to an increase in crack growth rate in Ti-6Al-4V alloys [24,60]. However, in this study, the disorientation between surrounding grains has a low correlation coefficient with the short crack growth rate. As a result, it can be said that there are no clusters of grains with similar orientations around the crack path.

\section{Discussion}

\subsection{Short crack path evaluation}

The microstructural features that induce a crack path in a specific crystallographic plane are still debatable in the literature $[27,61]$. In this section, by creating surrogate models, the relationship between the most contributing microstructural features that control the crack path on the basal or non-basal planes are specified using support vector machines [54] for both crack front regions. In the first region, short crack grows in most of the grains through the basal plane (red points in Figure 9(a)); cracking on the basal plane often occurs in grains with high basal Schmid factor surrounded by grains with relatively lower basal Schmid factors in the cyclic plastic zone (low $R B S_{c p}{ }^{A v e}$ and $R B S_{c p}{ }^{M a x}$ ). Figure 9(b) shows a representative cracked grain A with its surrounding grains. As the basal Schmid factor of the cracked grain decreases, the probability of having a crack growth on the non-basal plane increases. A high average basal Schmid factor of surrounding grains in the cyclic plastic zone may induce more slip activities on the non-basal plane, so crack growth on those planes occurs. The features that affect the crack in a facet-like path are similar to the features that lead to a growth on basal plane in the first region. 
Thus, growth on the basal plane leads to a growth in a facet-like path as reported by the previous studies $[22,23,62]$.

As the short crack front becomes larger in the second region, there is an increase in crack paths growing through grains on prismatic and pyramidal planes, which are defined as the non-basal planes (dark points in Figure 9(c)). As a result, there is a decrease in number of features that correlate with basal Schmid factors. A relatively high basal Schmid factor is still an important feature for crack growing on basal planes (grain E in Figure 9(d)); Moreover, a relatively high prismatic Schmid factor of grain in the monotonic plastic zone $\left(R P S_{m p}{ }^{M a x}\right)$ and a high average disorientation of grains in contact $\left(D O_{i c}{ }^{A v e}\right)$ are associated with a crack path on the basal plane. It was observed that a high basal Schmid factor of grains away from the crack front leads to crack bifurcations and to formation of secondary cracks but the high disorientation with the surrounding grains results in their arrest. Similar to the crack path on the basal plane, crack grows in a facetlike path in grains with high basal Schmid factor which are surrounded by grains with a high average disorientation in the monotonic plastic zone.

\subsection{Microstructural features relationship with short crack growth behavior}

A low crack growth rate with low variation leads to a better fatigue lifetime with a predictable fatigue crack growth, respectively. In this section, the relationship between most contributing microstructural features leading to an optimum ACGR and CGSD will be determined. The $3 \mathrm{D}$ response surface curve and its projection were employed to visualize the trend in those features with respect to the crack growth and its variation. The contour projection of the response surface curve for ACGR with respect to cracked grain shape $(F 2)$ and grains in contact with it $\left(n_{\text {ic }}\right)$ are shown in Figure 10(a). The data show that a decrease in $F 2$, which is an increase in grain's length in the loading direction 
(grain $\mathrm{G}$ in Figure 10(b)) with an increase in number of grains in contact lead to a low ACGR. For longer grains, a higher number of grains in contact do not induce a further decrease in the ACGR.

As the short crack length increases in the second region, a relatively high average Schmid factor of the grains in the monotonic plastic zone $\left(R S_{m p}{ }^{A v e}\right)$ as compared to the cracked grain $(S)$ results in the formation of secondary cracks and bifurcations (features of grain $\mathrm{K}$ in Figures $10(\mathrm{c})$ and (d)), which leads to a decrease in crack driving forces and the ACGR.

Figure 11(a) shows that as the average and maximum Schmid factors of grains in the cyclic plastic zone $\left(R S_{c p}{ }^{A v e}\right.$ and $R S_{c p}{ }^{M a x}$, respectively) become lower than the cracked grain, the CGSD decreases. This may impose a uniform crack growth inside the cracked grain (grain G in Figure 11(b)) that has a higher basal Schmid factor as compared to the surrounding grains in the cyclic plastic zone. Moreover, low number of grains in the cyclic plastic zone $\left(n_{\mathrm{pc}}\right)$, which leads to a higher fraction of $\alpha+\beta$ phase, induces a decrease in the variation of crack growth rate.

As the short crack front becomes larger, long cracked grains along the thickness (low $F 1$ ) with lower surface area than the largest grain in contact (high $R A_{i c}{ }^{M a x}$ ) lead to a low CGSD (features of grain K in Figure 11(c)). The grain in contact with a high surface area (grain P in Figure 11(d)) may induce a uniform strain to the cracked grain as compared to small grains with different shapes and crystallographic orientations.

\subsection{Microstructural mechanisms controlling the short crack behavior}

The microstructural features that control the short crack path, growth rate and its variation were determined. Here, the relationship between those features and short crack are discussed in order to reveal the possible microstructural mechanisms that may induce 
a specific crack path, low ACGR, and low CGSD.

Some studies have suggested that growth on a cluster of grains with high basal Schmid factors leads to growth on basal planes in facet-like paths that results in a high crack growth rate $[16,23,63]$. In this study, the microstructural features leading to short crack growth on the basal plane in a facet-like path are also similar. However, the microstructural features correlating with the crack path and ACGR are different (Figure 7 versus Figure 8, respectively); therefore, crack growth on a basal plane does not necessarily lead to high ACGR.

In contrast, it was revealed that the average crack growth rate depends on the cracked grain shape and the grains in contact with it. The cracked grain G in Figure 10(b) is elongated in the loading direction with 28 grains that are in contact with it. Fourteen of those grains are enclosed in the monotonic and cyclic plastic zone, so they are subjected to high plastic deformations. The remaining 14 grains are in contact with the cracked grain and they are still in the elastic region with no plastic deformation. Therefore, those grains impose a local constraint on the plastically deformed grains including the cracked grain.

It is presumed that accumulated damage in grains is caused by a combination of shear and tensile stress $[16,23]$. Thus, the local constraint imposed by the grains in contact decreases the tensile stress required for damage and cracking, so the crack growth rate is decreased $[59,64]$. In other words, those grains in contact may induce a local crack closure leading to a decrease in crack opening levels and ACGR. However, after reaching a certain number of grains in the elastic region, the level of constraint imposed by those grains may reach a constant level, so ACGR will not further decrease (see points at low $F 2$ with different $n_{\text {ic }}$ in Figure 10(a)). 
Regarding the crack growth rate variation, it was found that lower numbers of $\alpha$ grains in the cyclic plastic zone, which results in higher fraction of $\alpha+\beta$ phase, lead to lower CGSD (Figure 11(a)). It has been reported that an increase in $\alpha+\beta$ phase fraction causes a lower variation in crack growth rate [65-67]. This increase may induce a more uniform distribution of strain due to the existence of successive $\alpha$ and $\beta$ laths within a $\alpha+\beta$ grain as compared to only a primary $\alpha$ grain with few possible slip systems $[66,68]$. In addition, this analysis shows that a low shear stress field induced by those $\alpha$ grains is necessary for a low crack growth variation.

As the short crack length increases in the second region, there is an increase in plastic zone sizes so that a higher number of grains are subjected to plastic deformation and the aforementioned effect of local crack closure for long grains may decrease. However, it was observed that crack bifurcations and secondary cracks are formed in grains enclosed in the monotonic plastic zone that have much higher Schmid factors than the cracked grain. Thus, there is a sudden increase in the shear stress field from the cracked grain towards the grains in the monotonic plastic zone (Figure 10(d)). This distribution of the stress field causes crack formation within the plastic zone that induces a decrease in the crack driving forces, leading to a lower ACGR.

A long cracked grain along the thickness has a lower variation in the plastic zone along the crack front which leads to a stable crack front growth inside the grain. Moreover, grains in contact with high surface areas along the thickness lead to a more uniform strain distribution around the crack front as compared to small grains with different shapes and sizes, which results in a low CGSD (Figure 11(d)). 


\section{Conclusions}

In this study, the complex 3D microstructure and short crack were characterized and linked in detail by employing the X-ray micro-tomography and serial sectioning using EBSD analysis. Subsequently, the microstructural features contribution to the short crack growth behavior were ranked and coarsened by using global sensitivity and principal component analysis. Afterwards, by creating surrogate models, the relationship between the most contributing microstructural features and short crack growth behavior were further analyzed via support vector machines.

It was clarified that short crack path and its growth rate are strongly affected by the interactions with neighboring grains. Short crack path on a basal plane in a facet-like path depends on the basal Schmid factor of the cracked grain and the neighboring grains enclosed in the cyclic plastic zone. However, those crystallographic and fracture paths do not necessarily induce a high average crack growth rate or variation. A high number of grains in contact with a long cracked grain in the loading direction imposes a constraint on the tensile stress that is necessary for damage and cracking, so it induces a decrease in the average crack growth rate. On the other hand, a low number of $\alpha$ grains (high $\alpha+\beta$ fraction) with a low Schmid factor in the cyclic plastic zone induce a uniform strain distribution that leads to low crack growth rate variation.

As the short crack front becomes larger, there is a decrease in the interaction with a change in microstructural features controlling the short crack growth behavior. It was concluded that the high shear stress of the grains in the monotonic plastic zones leads to crack bifurcation and secondary cracks which induce a decrease in crack driving forces resulting in a decrease in average crack growth rate. On the other hand, those bifurcations 
and secondary crackings induce a moderate interaction with the crystallographic features of neighboring grains.

To summarize, a combination of different complex microstructural features control the shear and tensile stress fields resulting in short crack growth rate variation. The current approach can be applied to extract the predominant 3D complex microstructural features controlling the mechanical properties (e.g. localized deformation, crack behavior, etc.) in a wide range of polycrystalline alloys. The relationship between those features and mechanical behavior can be analyzed. Finally, the microstructural mechanisms that control the mechanical response can be revealed.

\section{Acknowledgments}

The synchrotron radiation experiments were performed at SPring- 8 with the approval of the Japan Synchrotron Radiation Research Institute (JASRI) through proposal number of 2016A0076, 2016B0076 and, 2016A0076. This work was supported by the Grant-in-aid from Structural Materials for Innovation (SM4I) of the Cross-ministerial Strategic Innovation Promotion (SIP) Program. The authors gratefully acknowledge the support of the Light Metal Educational Foundation (LMEF).

\section{References}

[1] D. Banerjee, J.C. Williams, Perspectives on titanium science and technology, Acta Mater. 61 (2013) 844-879.

[2] Y. Akiniwa, K. Tanaka, E. Matsui, Statistical characteristics of propagation of small fatigue cracks in smooth specimens of aluminium alloy 2024-T3, Mater. Sci. Eng. A. 104 (1988) 105-115.

[3] E.R.D.L. Rios, H. Mohamed J., K.J. Miller, a Micro-Mechanics Analysis for 
Short Fatigue Crack Growth, Fatigue Fract. Eng. Mater. Struct. 8 (1985) 49-63. doi:10.1111/j.1460-2695.1985.tb00419.x.

[4] K.J. Miller, Materials science perspective of metal fatigue resistance, Mater. Sci. Technol. 9 (1993) 453-462. doi:10.1179/026708393790172178.

[5] J. Lankford, The Growth of Small Fatigue Cracks in 7075-T6 Aluminum, Fatigue Eng. Mater. Struct. 5 (1982) 233-248. doi:10.1111/j.14602695.1982.tb01251.x.

[6] J. Lankford, the Influence of Microstructure on the Growth of Small Fatigue Cracks, Fatigue Fract. Eng. Mater. Struct. 8 (1985) 161-175. doi:10.1111/j.1460-2695.1985.tb01201.x.

[7] T. Zhai, A.J. Wilkinson, J.W. Martin, A crystallographic mechanism for fatigue crack propagation through grain boundaries.pdf, 48 (2000) 4917-4927.

[8] T. Zhai, X.P. Jiang, J.X. Li, M.D. Garratt, G.H. Bray, The grain boundary geometry for optimum resistance to growth of short fatigue cracks in high strength Al-alloys, Int. J. Fatigue. 27 (2005) 1202-1209. doi:10.1016/j.ijfatigue.2005.06.021.

[9] M. Hassanipour, S. Watanabe, K. Hirayama, H. Toda, K. Uesugi, A. Takeuchi, Short Crack Growth Behavior and its Transitional Interaction with 3D Microstructure in Ti-6Al-4V, Mater. Sci. Eng. A. 738 (2018) 229-237. doi:10.1016/j.msea.2018.09.073.

[10] K. Tokaji, T. Ogawa, K. Ohya, The effect of grain size on small fatigue crack growth in pure titanium, Int. J. Fatigue. 16 (1994) 571-578. doi:10.1016/01421123(94)90483-9.

[11] R.K. Nalla, J.P. Campbell, R.O. Ritchie, Mixed-mode, high-cycle fatigue-crack 
growth thresholds in Ti-6Al-4V: Role of small cracks, Int. J. Fatigue. 24 (2002) 1047-1062. doi:10.1016/S0142-1123(02)00020-8.

[12] A. Pilchak, A. Bhattacharjee, The Effect of Microstructure on Fatigue Crack Initiation in Ti-6Al-4V, ICF12, Ottawa 2012. 2 (2013) 1-10. http://www.gruppofrattura.it/ocs/index.php/ICF/ICF12/paper/view/1623/9093.

[13] K. Nakajima, K. Terao, T. Miyata, The effect of microstructure on fatigue crack propagation of $\alpha+\beta$ titanium alloys, Mater. Sci. Eng. A. 243 (1998) 176-181. doi:10.1016/S0921-5093(97)00797-1.

[14] K. Tanaka, Y. Akiniwa, Propagation and non-propagation of small fatigue cracks, in: ICF7, Houst. 1989, 1989.

[15] R.O. Ritchie, Near-threshold fatigue-crack propagation in steels, Int. Met. Rev. 24 (1979) 205-230. doi:10.1179/imtr.1979.24.1.205.

[16] I. Bantounas, D. Dye, T.C. Lindley, The effect of grain orientation on fracture morphology during high-cycle fatigue of Ti-6Al-4V, Acta Mater. 57 (2009) $3584-3595$.

[17] A.W. Thompson, W.A. Backofen, The effect of grain size on fatigue, Acta Metall. 14A (1971) 597-606. doi:10.1016/0001-6160(71)90012-5.

[18] X. Demulsant, J. Mendez, Influence of environment on low cycle fatigue damage in Ti6A14V and Ti 6246 titanium alloys, Mater. Sci. Eng. A. 219 (1996) $202-211$.

[19] A.J. McEvily, THE GROWTH OF FATIGUE MCEVILY CRACKS : A REVIEW, Mater. Sci. Res. Int. 4 (1998) 3-11.

[20] Y. TANAKA, K., \& AKINIWA, Propagation and non-propagation of small fatigue cracks., in: Proc. 7th Int. Conf. Fract., 1989: pp. 869-887. 
[21] V. Sinha, M.J. Mills, J.C. Williams, Crystallography of fracture facets in a nearalpha titanium alloy, Metall. Mater. Trans. A. 37 (2006) 2015-2026.

[22] I. Bantounas, T.C. Lindley, D. Rugg, D. Dye, Effect of microtexture on fatigue cracking in Ti-6Al-4V, Acta Mater. 55 (2007) 5655-5665.

[23] F. Bridier, P. Villechaise, J. Mendez, Slip and fatigue crack formation processes in an $\alpha / \beta$ titanium alloy in relation to crystallographic texture on different scales, Acta Mater. 56 (2008) 3951-3962.

[24] K. Le Biavant, S. Pommier, C. Prioul, Local texture and fatigue crack initiation in a Ti-6Al-4V titanium alloy, Fatigue Fract. Eng. Mater. Struct. 25 (2002) 527545. doi:10.1046/j.1460-2695.2002.00480.x.

[25] E.E. Sackett, L. Germain, M.R. Bache, Crystal plasticity, fatigue crack initiation and fatigue performance of advanced titanium alloys, Int. J. Fatigue. 29 (2007) 2015-2021.

[26] H. Toda, E. Maire, S. Yamauchi, H. Tsuruta, T. Hiramatsu, M. Kobayashi, In situ observation of ductile fracture using X-ray tomography technique, Acta Mater. 59 (2011) 1995-2008. doi:10.1016/j.actamat.2010.11.065.

[27] S. Birosca, J.Y. Buffiere, M. Karadge, M. Preuss, 3-D observations of short fatigue crack interaction with lamellar and duplex microstructures in a two-phase titanium alloy, Acta Mater. 59 (2011) 1510-1522.

[28] W. Ludwig, A. King, P. Reischig, M. Herbig, E.M. Lauridsen, S. Schmidt, H. Proudhon, S. Forest, P. Cloetens, S.R. du Roscoat, J.Y. Buffière, T.J. Marrow, H.F. Poulsen, New opportunities for 3D materials science of polycrystalline materials at the micrometre lengthscale by combined use of X-ray diffraction and X-ray imaging, Mater. Sci. Eng. A. 524 (2009) 69-76. 
doi:10.1016/j.msea.2009.04.009.

[29] A. King, M. Herbig, W. Ludwig, P. Reischig, E.M. Lauridsen, T. Marrow, J.Y. Buffière, Non-destructive analysis of micro texture and grain boundary character from X-ray diffraction contrast tomography, Nucl. Instruments Methods Phys. Res. Sect. B Beam Interact. with Mater. Atoms. 268 (2010) 291-296. doi:10.1016/j.nimb.2009.07.020.

[30] M. Herbig, A. King, P. Reischig, H. Proudhon, E.M. Lauridsen, J. Marrow, J.Y. Buffire, W. Ludwig, 3-D growth of a short fatigue crack within a polycrystalline microstructure studied using combined diffraction and phase-contrast X-ray tomography, Acta Mater. 59 (2011) 590-601. doi:10.1016/j.actamat.2010.09.063.

[31] A. King, W. Ludwig, M. Herbig, J.Y. Buffire, A.A. Khan, N. Stevens, T.J. Marrow, Three-dimensional in situ observations of short fatigue crack growth in magnesium, Acta Mater. 59 (2011) 6761-6771. doi:10.1016/j.actamat.2011.07.034.

[32] G.M. Castelluccio, D.L. McDowell, Microstructure-sensitive small fatigue crack growth assessment: Effect of strain ratio, multiaxial strain state, and geometric discontinuities, Int. J. Fatigue. 82 (2015) 521-529. doi:10.1016/j.ijfatigue.2015.09.007.

[33] A. Fatemi, D.F. Socie, A critical plane approach to multiaxial fatigue damage including out of phase loading, Fatigue Fract. Eng. Mater. Struct. 11 (1988) $149-165$.

[34] G.M. Castelluccio, W.D. Musinski, D.L. McDowell, Computational micromechanics of fatigue of microstructures in the HCF-VHCF regimes, Int. J. 
Fatigue. 93 (2016) 387-396.

[35] H. Proudhon, J. Li, W. Ludwig, A. Roos, S. Forest, Simulation of Short Fatigue Crack Propagation in a 3D Experimental Microstructure, Adv. Eng. Mater. 19 (2017) 1-9. doi:10.1002/adem.201600721.

[36] H. Li, L. Gutierrez, H. Toda, O. Kuwazuru, W. Liu, Y. Hangai, M. Kobayashi, R. Batres, Identification of material properties using nanoindentation and surrogate modeling, Int. J. Solids Struct. 81 (2016) 151-159. doi:10.1016/j.ijsolstr.2015.11.022.

[37] I. Jolliffe, Principal component analysis, Int. Encycl. Stat. Sci. (2011) 10471149.

[38] R.G. Brereton, G.R. Lloyd, Support Vector Machines for classification and regression, Analyst. 135 (2010) 230-267. doi:10.1039/b918972f.

[39] R. Pippan, M. Berger, H.P. Stüwe, The influence of crack length on fatigue crack growth in deep sharp notches, Metall. Trans. A. 18 (1987) 429-435. doi:10.1007/BF02648804.

[40] M. Kobayashi, H. Toda, Y. Kawai, T. Ohgaki, K. Uesugi, D.S. Wilkinson, T. Kobayashi, Y. Aoki, M. Nakazawa, High-density three-dimensional mapping of internal strain by tracking microstructural features, Acta Mater. 56 (2008) 21672181. doi:10.1016/j.actamat.2007.12.058.

[41] I.R. JC Newman, Stress-intensity factor equations for cracks in threedimensional finite bodies, Fract. Mech. Fourteenth Symp. I Theory Anal. ASTM STP791. (1983).

[42] T.L. Anderson, Fracture Mechanics: Fundamentals and Applications, CRC Press, 2017. 
[43] E. Gumbel, Statistics of extremes, 2012.

[44] A. Saltelli, M. Ratto, T. Andres, F. Campolongo, J. Cariboni, D. Gatelli, M. Saisana, S. Tarantola, Global Sensitivity Analysis. The Primer, 2007. doi:10.1002/9780470725184.

[45] a Saltelli, S. Tarantola, K. Chan, A quantitative model-independent method for global sensitivity analysis of model output, Technometrics. 41 (1999) 39-56. doi:10.1080/00401706.1999.10485594.

[46] B. Iooss, P. Lemaître, A review on global sensitivity analysis methods, (2014). http://arxiv.org/abs/1404.2405.

[47] J. Lee Rodgers, W. Alan Nice Wander, Thirteen ways to look at the correlation coefficient, Am. Stat. 42 (1988) 59-66. doi:10.1080/00031305.1988.10475524.

[48] R. Taylor, Interpretation of the correlation coefficient: a basic review, J. Diagnostic Med. Sonogr. 6 (1990) 35-39.

[49] C. Cortes, V. Vapnik, Support-Vector Networks, Mach. Learn. 20 (1995) 273297. doi:10.1023/A:1022627411411.

[50] and A.T. M. Mohri, A. Rostamizadeh, Foundations of Machine Learning, Second, MIT Press, 2018.

[51] T. Hastie, R. Tibshirani, J. Friedman, The Elements of Statistical Learning, Math. Intell. (2008) 764. doi:10.1198/jasa.2004.s339.

[52] C.-C. Chang, C.-J. Lin, Libsvm, ACM Trans. Intell. Syst. Technol. 2 (2011) 127. doi:10.1145/1961189.1961199.

[53] Chih-Wei Hsu, Chih-Chung Chang, C.-J. Lin, and C.-J.L. Chih-Wei Hsu, Chih-Chung Chang, Chih-Wei Hsu, Chih-Chung Chang, C.-J. Lin, A Practical Guide to Support Vector Classification, BJU Int. 101 (2008) 1396-1400. 
doi:10.1177/02632760022050997.

[54] S. jin Wang, A. Mathew, Y. Chen, L. feng Xi, L. Ma, J. Lee, Empirical analysis of support vector machine ensemble classifiers, Expert Syst. Appl. 36 (2009) 6466-6476. doi:10.1016/j.eswa.2008.07.041.

[55] D.. Nghi, L.C. Mai, Training Data Selection for Support Vector Machines Model, 2011 Int. Conf. Inf. Electron. Eng. 6 (2011) 28-32. http://www.ipcsit.com/vol6/6-E012.pdf.

[56] A.J. and B.S. SMOLA, A tutorial on support vector regression, Stat. Comput. (2004) 199-222. doi:10.1023/B:STCO.0000035301.49549.88.

[57] T.O. Kowang, C.S. Long, A. Rasli, Innovation management and performance framework for research university in Malaysia, Int. Educ. Stud. 8 (2015) 32-45. doi:10.5539/ies.v8n6p32.

[58] A. Navarro, E.R. Rios, A microstructurally short fatigue crack growth equation, Fatigue Fract. Eng. Mater. Struct. 11 (1988) 383-396.

[59] S. Suresh, R.O. Ritchie, Propagation of short fatigue cracks, Int. Met. Rev. 29 (1984) 445-475. doi:10.1179/imtr.1984.29.1.445.

[60] V. Sinha, M.J. Mills, J.C. Williams, J.E. Spowart, Observations on the faceted initiation site in the dwell-fatigue tested Ti-6242 alloy: crystallographic orientation and size effects, Metall. Mater. Trans. A. 37 (2006) 1507-1518.

[61] F. Bridier, P. Villechaise, J. Mendez, Analysis of the different slip systems activated by tension in a $\alpha / \beta$ titanium alloy in relation with local crystallographic orientation, Acta Mater. 53 (2005) 555-567.

[62] A.L. Pilchak, Fatigue crack growth rates in alpha titanium: faceted vs. striation growth, Scr. Mater. 68 (2013) 277-280. 
[63] C.J. Szczepanski, S.K. Jha, J.M. Larsen, J.W. Jones, Microstructural influences on very-high-cycle fatigue-crack initiation in Ti-6246, Metall. Mater. Trans. A Phys. Metall. Mater. Sci. 39 (2008) 2841-2851. doi:10.1007/s11661-008-9633$\mathrm{Z}$.

[64] A.J. McEvily, K. Minakawa, Crack closure and the growth of short and long fatigue cracks, Scr. Metall. 18 (1984) 71-76. doi:10.1016/0036-9748(84)900929.

[65] G. Lütjering, Influence of processing on microstructure and mechanical properties of $(\alpha+\beta)$ titanium alloys, Mater. Sci. Eng. A. 243 (1998) 32-45. doi:10.1016/S0921-5093(97)00778-8.

[66] C.P. Przybyla, Microstructure-Sensitive Extreme Value Probabilities of Fatigue in Advanced Engineering Alloys, 2010.

[67] S. Ivanova, R.R. Biederman, R.D.S. Jr, Investigation of Fatigue Crack Initiation in Ti-6Al-4V During Tensile-Tensile Fatigue Investigation of Fatigue Crack Initiation in Ti-6Al-4V During Tensile-Tensile Fatigue, J. Mater. Eng. Perform. $11(2002)$ 226-231.

[68] K.S. Ravichandran, Near threshold fatigue crack growth behavior of a titanium alloy: Ti-6A1-4V, Acta Metall. Mater. 39 (1991) 401-410. doi:10.1016/09567151(91)90319-V. 


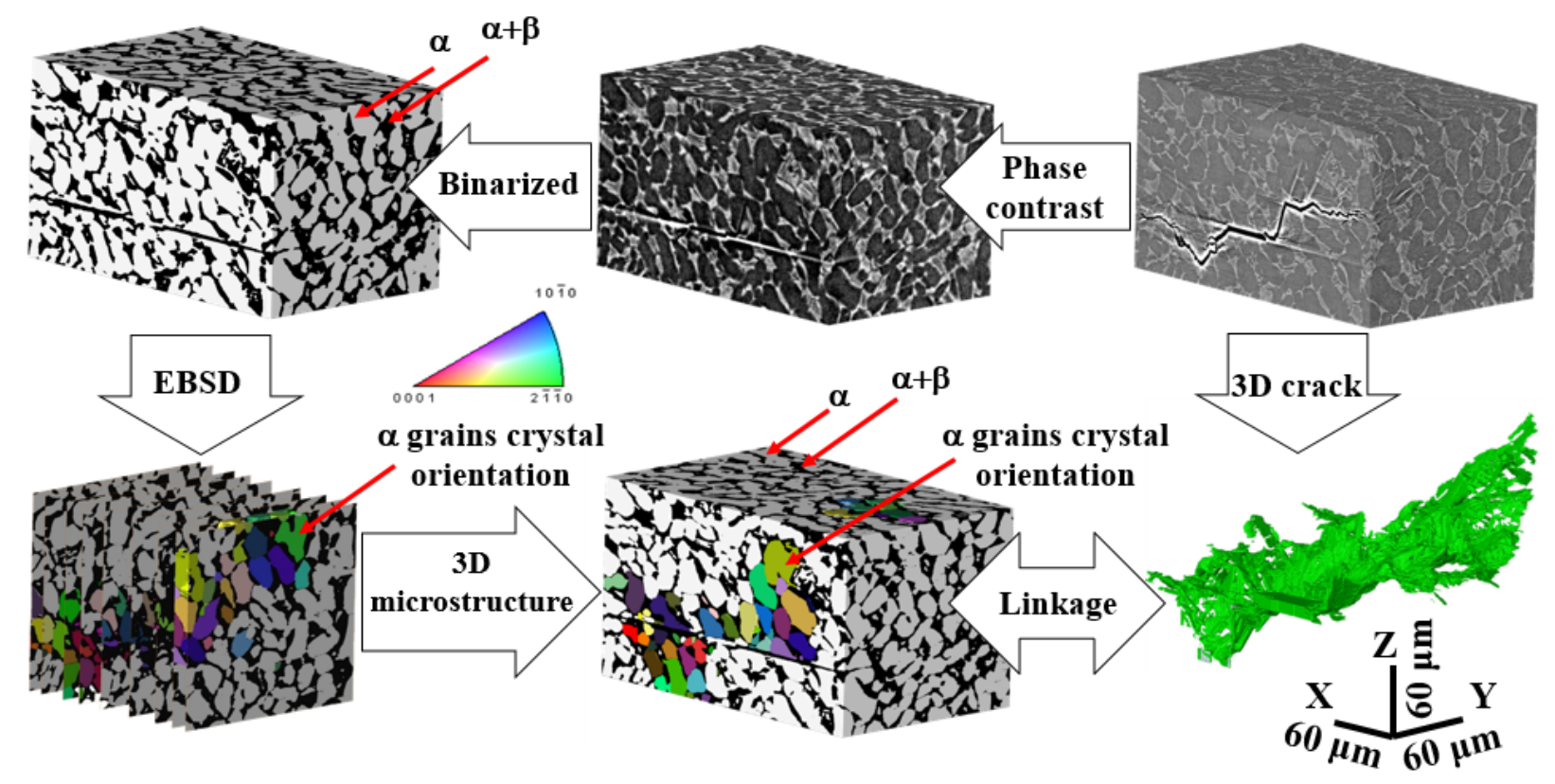

Figure 1. Procedure of 3D microstructural features and short crack reconstruction and linkage. The grains colors correspond to the inverse pole figure (IPF) map.

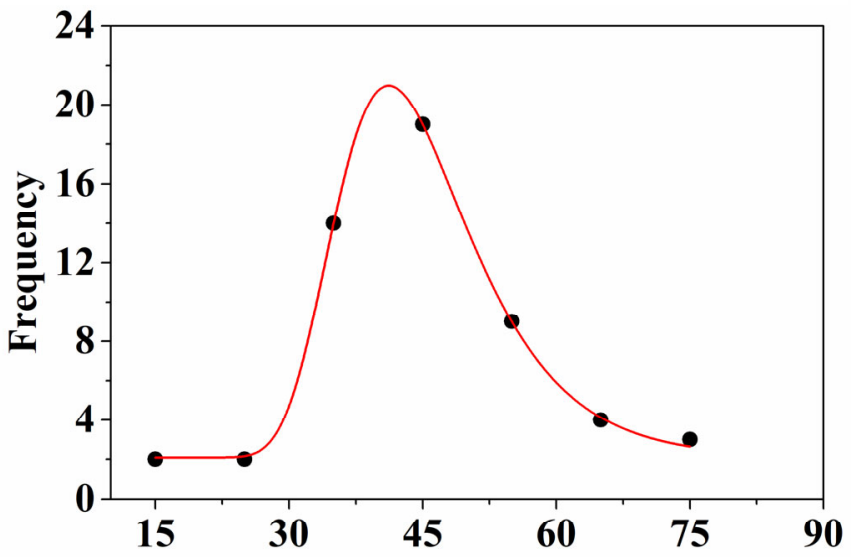

Disorientation of grains in contact (degrees)

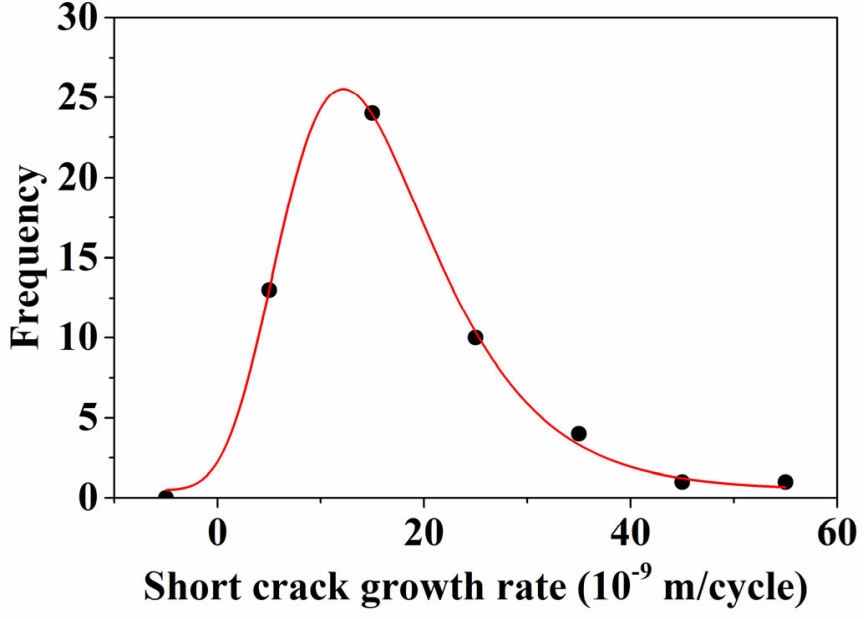

(b)

Figure 2. Histogram of the quantified data with the Gumbel density function fit, (a) disorientation of grains in contact with the cracked grain, and (b) short crack growth rate. 


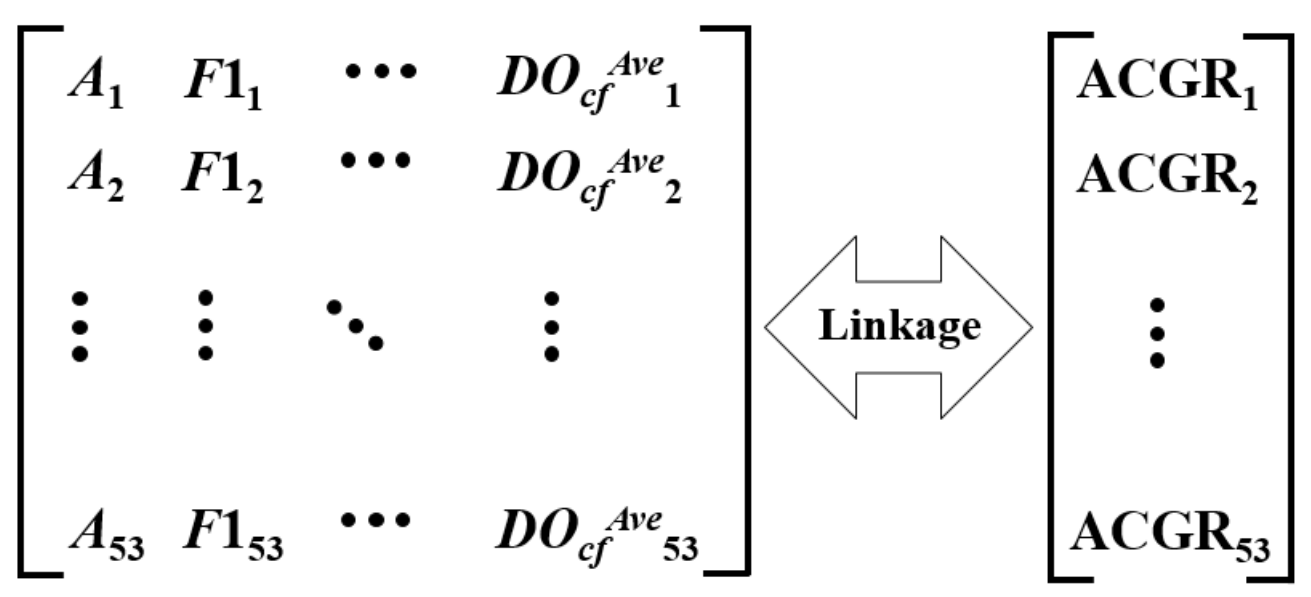

Figure 3. Matrix of 77 microstructural features (row) in 53 cracked grains (column) linked to their corresponding average crack growth rate (ACGR) along the crack front.

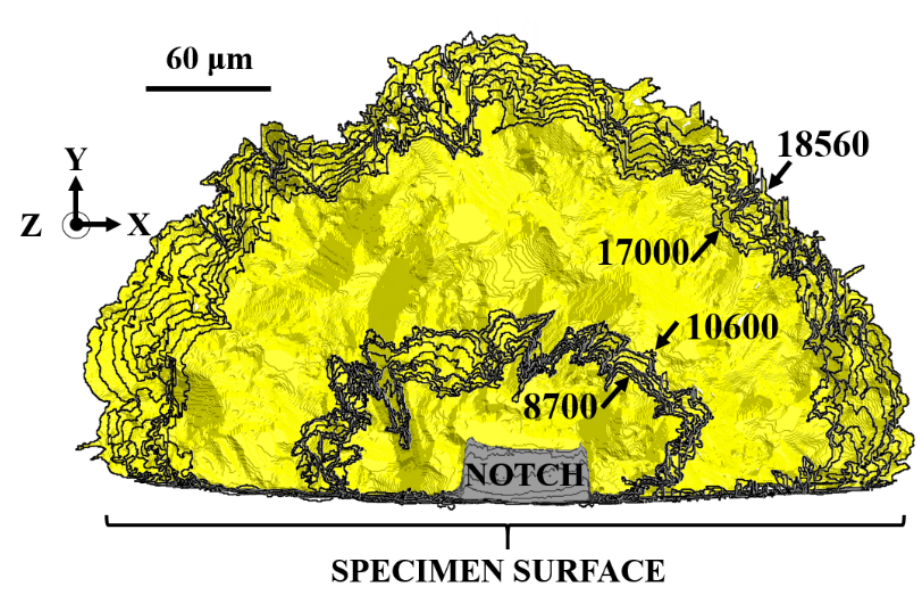

(a)

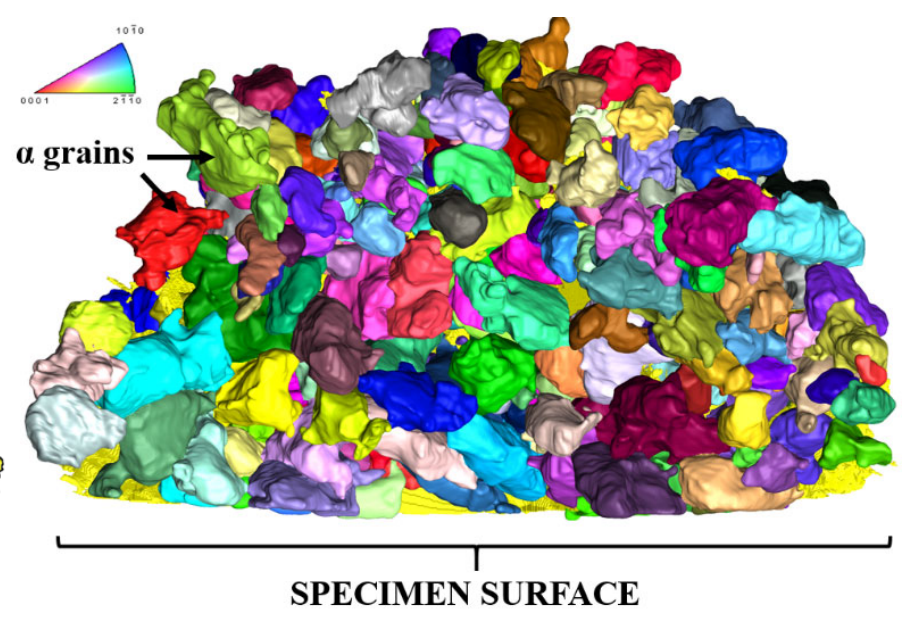

(b)

Figure 4. Three dimensional images projections on the xy plane, (a) short crack growing from 8700 to 10600 cycles in the first region to a longer length ranging from 17000 to 18560 cycles in the second region (distance between each line corresponds to $5 \mu \mathrm{m}$ crack growth) [9]. (b) Three dimensional $\alpha$ grains projection on xy plane covering the 3D crack (grains colors correspond to the IPF map). 


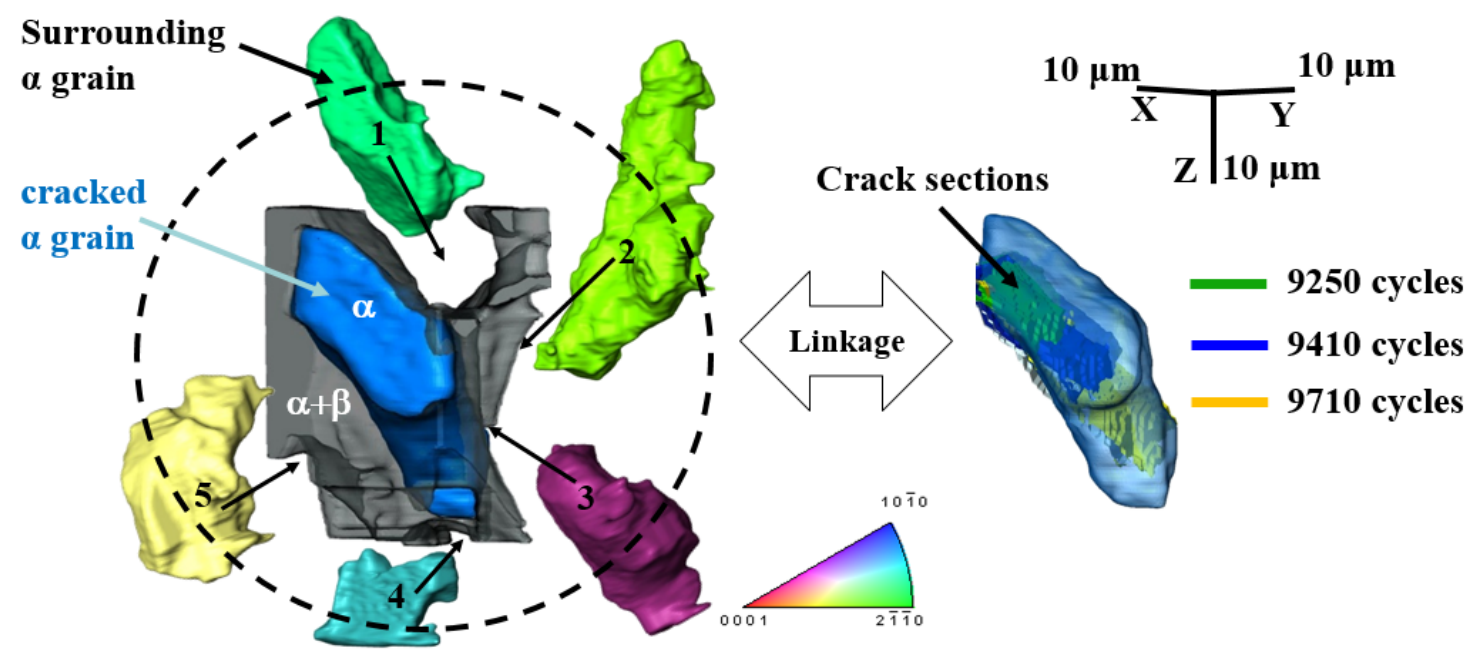

Figure 5. Correlation between the reconstructed cracked grain with its surrounding microstructure ( $\alpha+\beta$ phase and $\alpha$ grains) and short crack growth behavior is investigated (grains colors correspond to the IPF map).

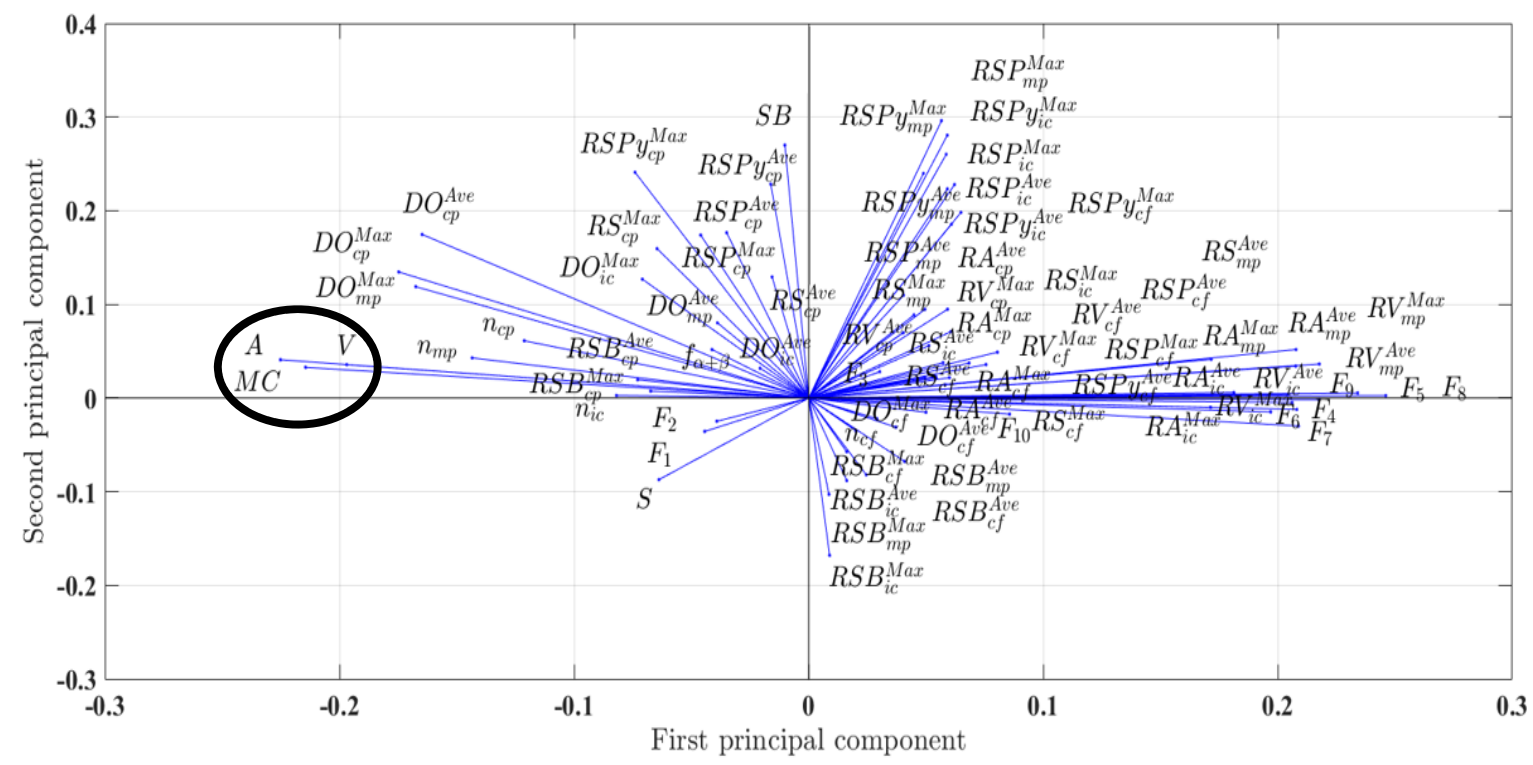

Figure 6. Principal component analysis (PCA) for all microstructural features corresponding to the 53 cracked grain and their 265 surrounding grains. 


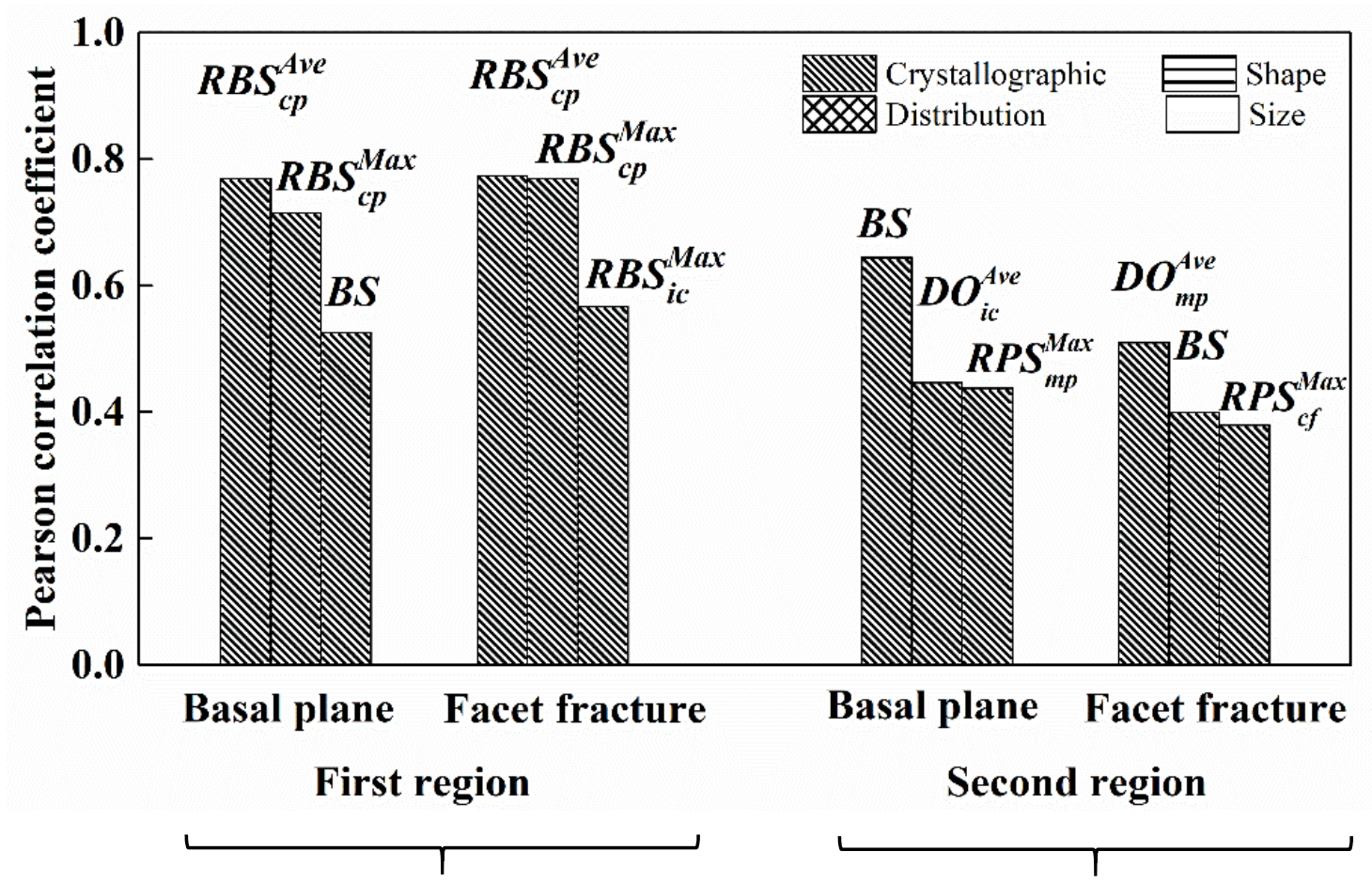

(a)

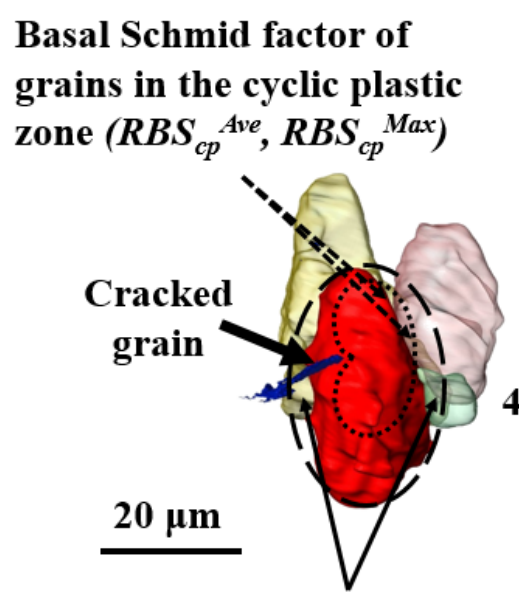

Basal Schmid of grains in contact $\left(R_{B S_{i c}}^{\max }\right)$

(b)

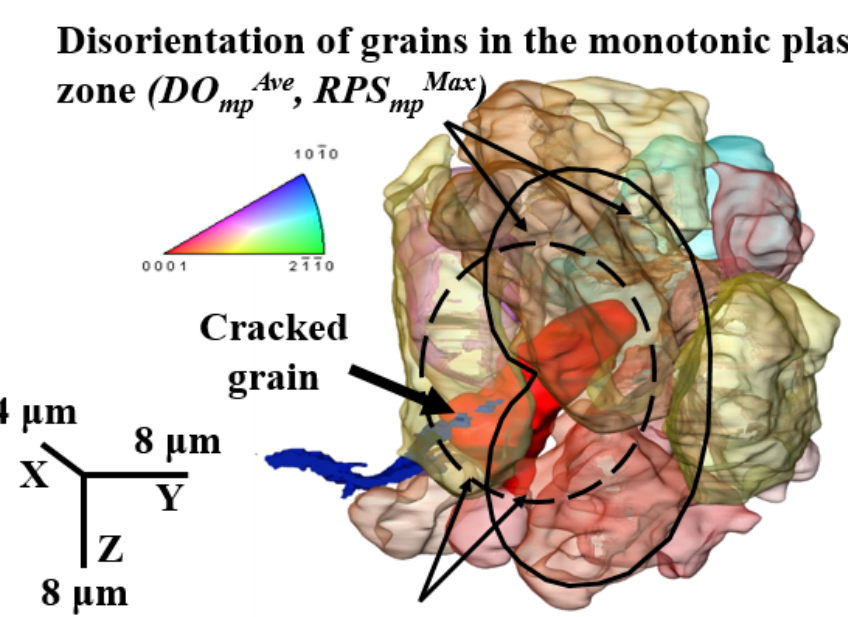

Disorientation of grains in contact $\left(\mathrm{DO}_{\left.i c^{\max }\right)}\right.$

(c)

Figure 7. (a) Correlation between three microstructural features having the highest

Pearson correlation coefficients with short crack path on the basal plane and in a facet-

like fracture in the first and second regions. Short crack path is associated with (b)

basal Schmid factor of grains crystallographic features in the cyclic plastic zone and those in contact in the first region as compared to (c) disorientation of grains in the monotonic plastic zone and those in contact for the longer short crack in the second region (grains colors correspond to the IPF map). 


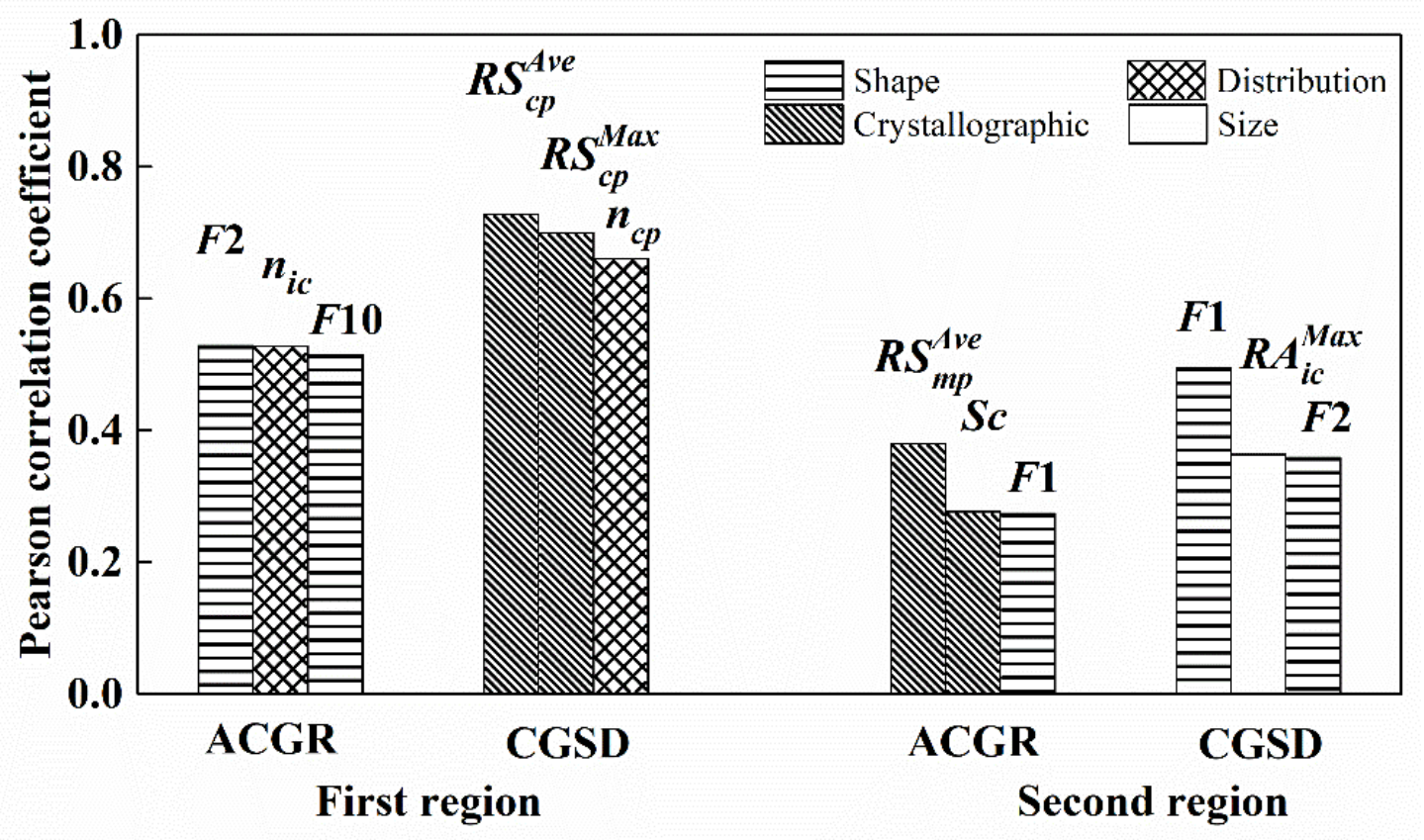

(a)

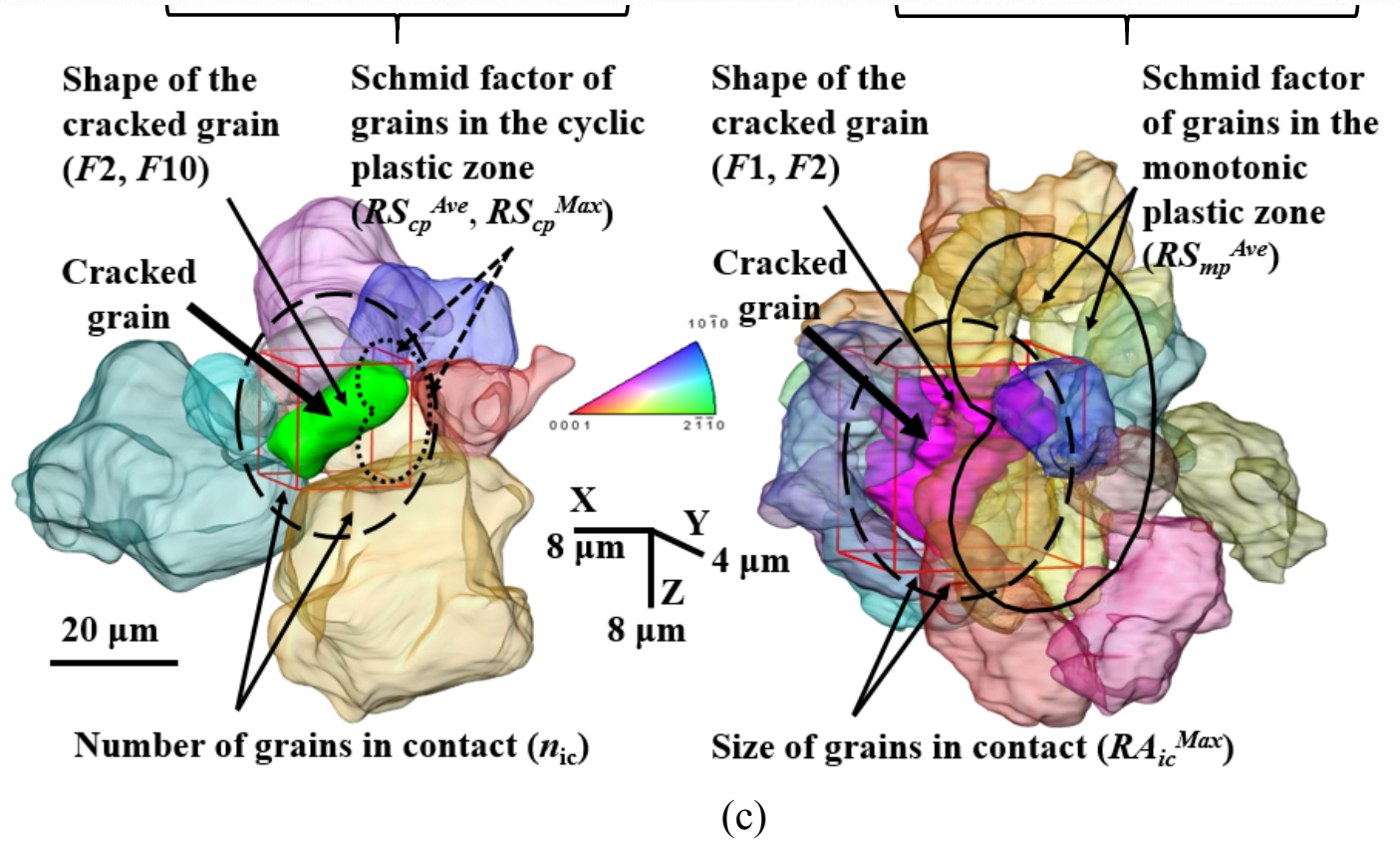

Figure 8. (a) Correlation between three microstructural features having the highest

Pearson correlation coefficients with average crack growth rate (ACGR) and crack growth rate standard deviation (CGSD) in the first and second regions. (b) Average crack growth rate and its variation are associated with shape of the cracked grain, grains in contact in both regions. (c) As the short crack grows into the second region, the interaction with crystallpgraphic features extends from the cyclic plastic zone to the monotonic one (grains colors correspond to the IPF map). 


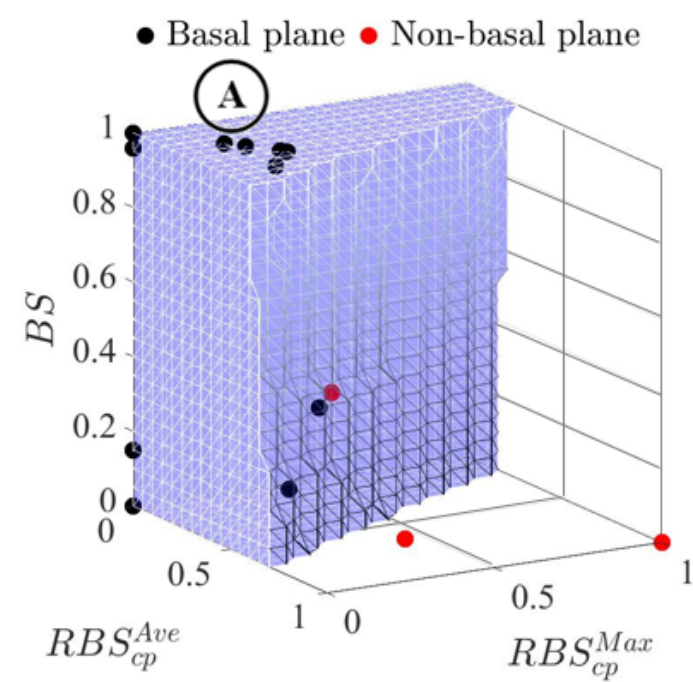

(a)

- Basal plane $\bullet$ Non-basal plane

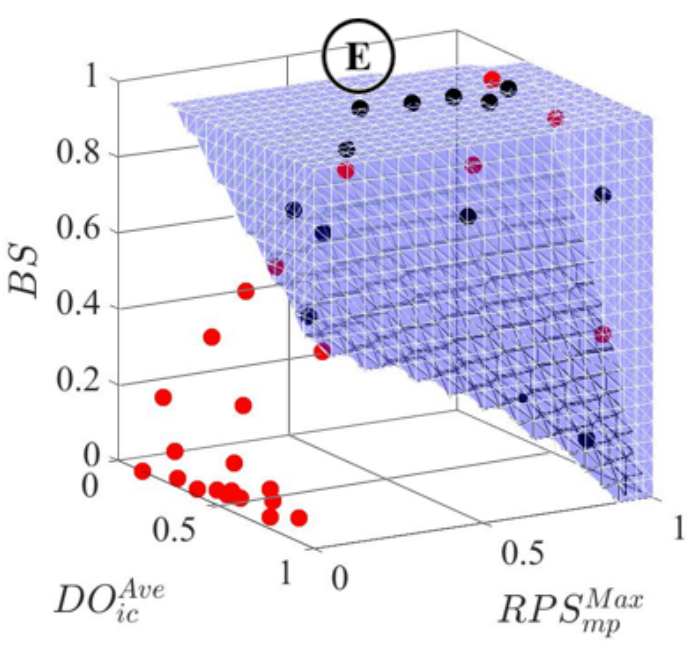

(c)

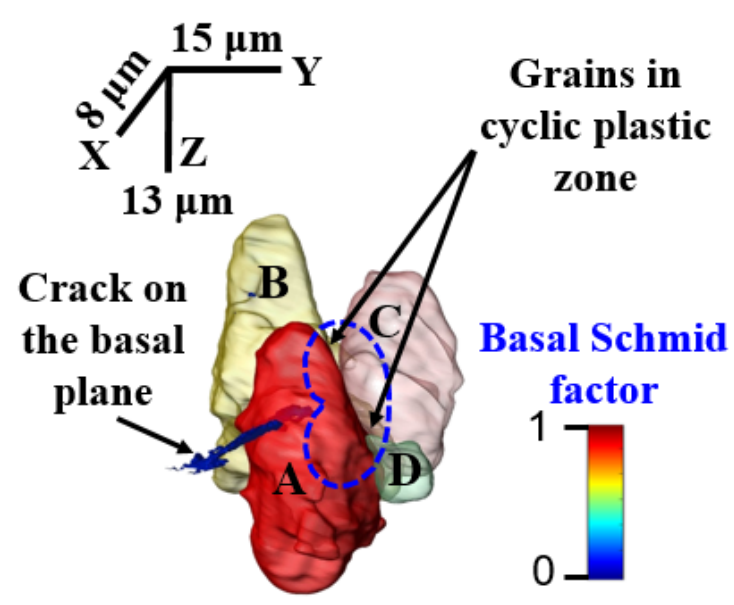

(b)

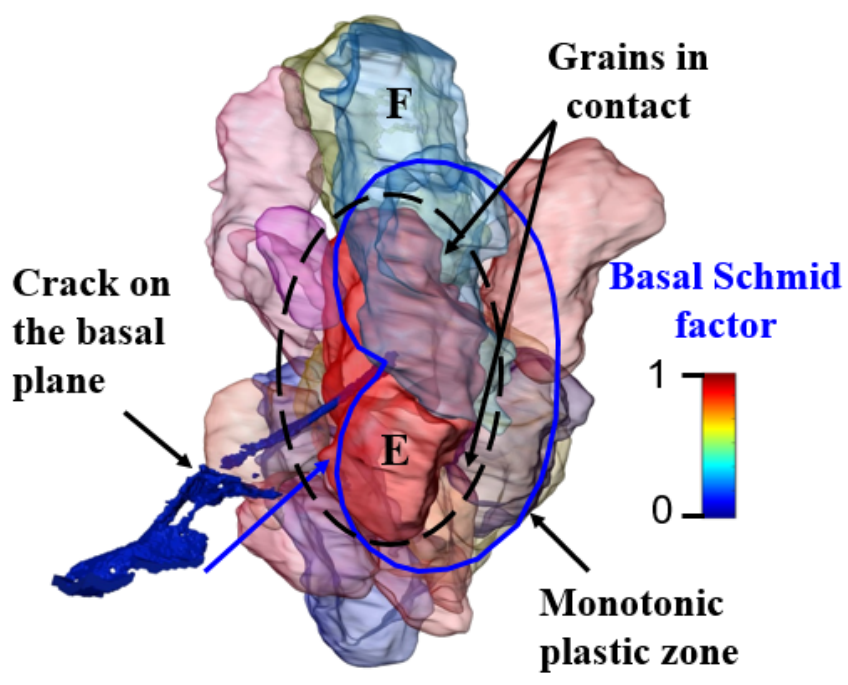

(d)

Figure 9. Three most contributing microstructural features leading to crack paths on

basal planes for two short crack front regions. (a) Relationship between those features

in the first region and (b) cracked grain A with high basal Schmid factor $(B S)$

surrounded by grain B, C, and D in the cyclic plastic zone with low average and maximum basal Schmid factor $\left(R B S_{c p}^{A v e}\right.$ and $R B S_{c p}{ }^{M a x}$, respectively). (c) Relationship between features for the longer short crack in the second region, (d) cracked grain E with high basal Schmid $(B S)$ factor surrounded by grain $\mathrm{F}$ with a high prismatic Schmid factor in the monotonic plastic zone $\left(R P S_{m p}{ }^{M a x}\right)$ and high average misorientation

$$
\left(D O_{i c}{ }^{A v e}\right) \text {. }
$$


- Grain features - Optimum features

ACGR

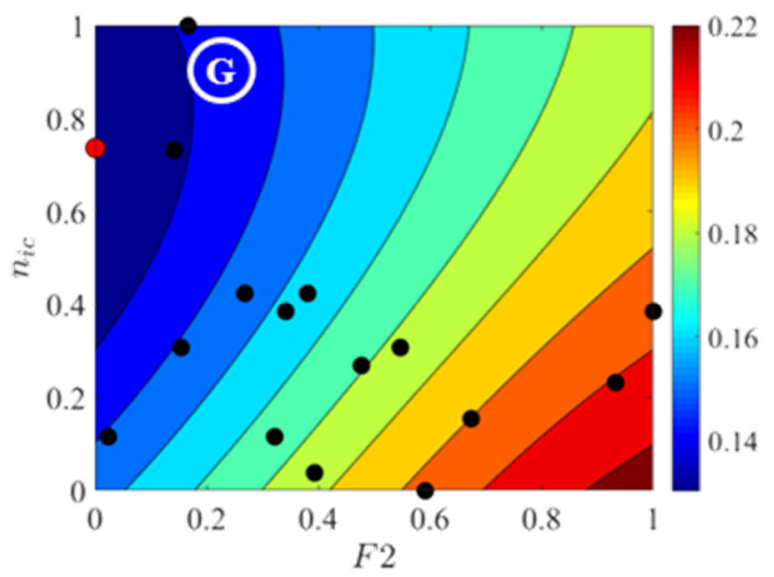

(a)

ACGR

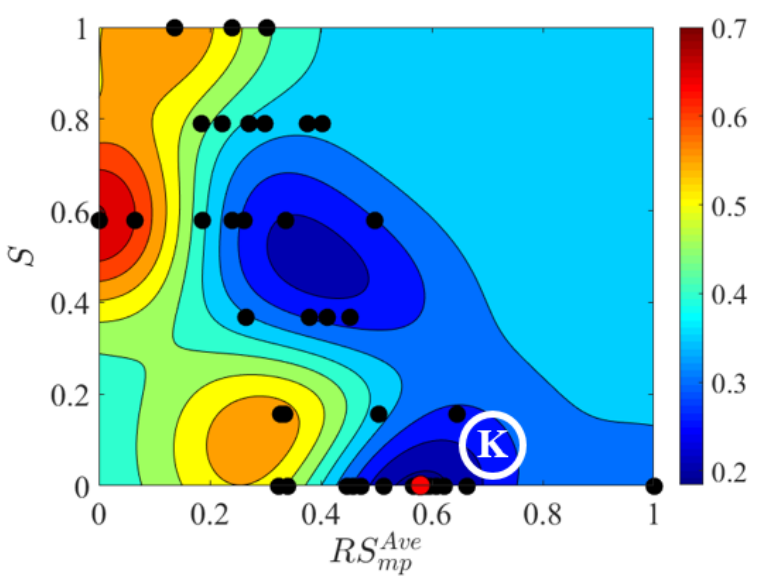

(c)

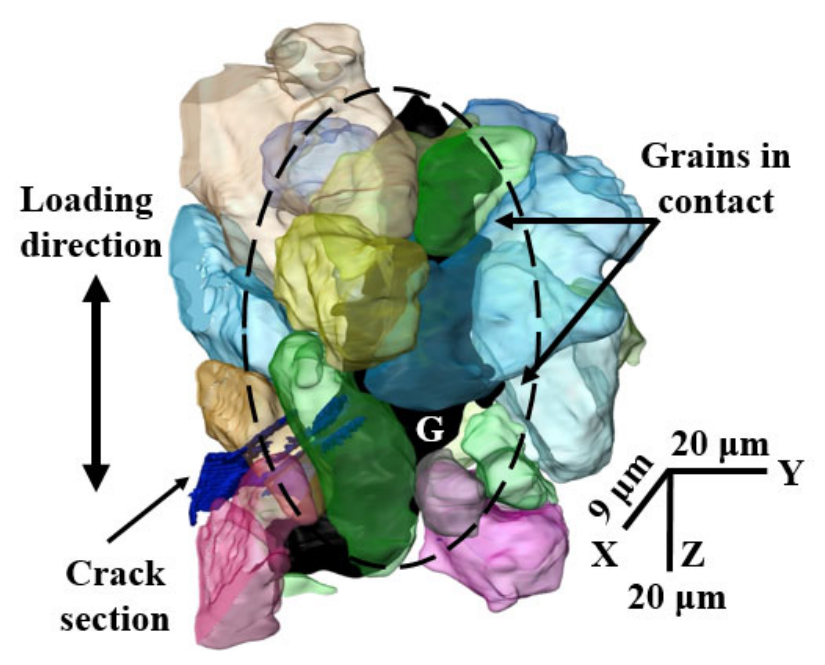

(b)

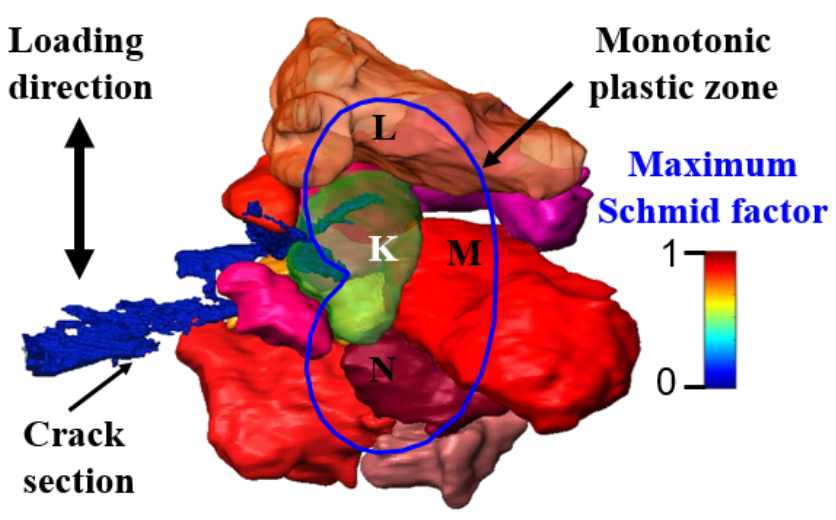

(d)

Figure 10. Contour projection of the 3D response surface curve for the two most contributing features to the average crack growth rate (ACGR). (a) Relationship between grain shape and surrounding grains distribution ( $F 2$ and $n_{\text {ic }}$, respectively) features with respect to ACGR in the first region. (b) Cracked grain G elongated in the loading direction (low F2) with many grains in contact with it ( $\left.n_{\text {ic }}\right)$ has low ACGR. (c) Relationship between Schmid factor of grain and its surrounding grains ( $S$ and $R S_{m p}{ }^{A v e}$ ) with respect to ACGR for the longer short crack. (d) Cracked grain K with low Schmid factor $(S)$ is surrounded by grains $\mathrm{L}, \mathrm{M}$, and $\mathrm{O}$ in the monotonic plastic zone with high average Schmid factor $\left(R S_{m p}{ }^{A v e}\right)$ has low ACGR. 


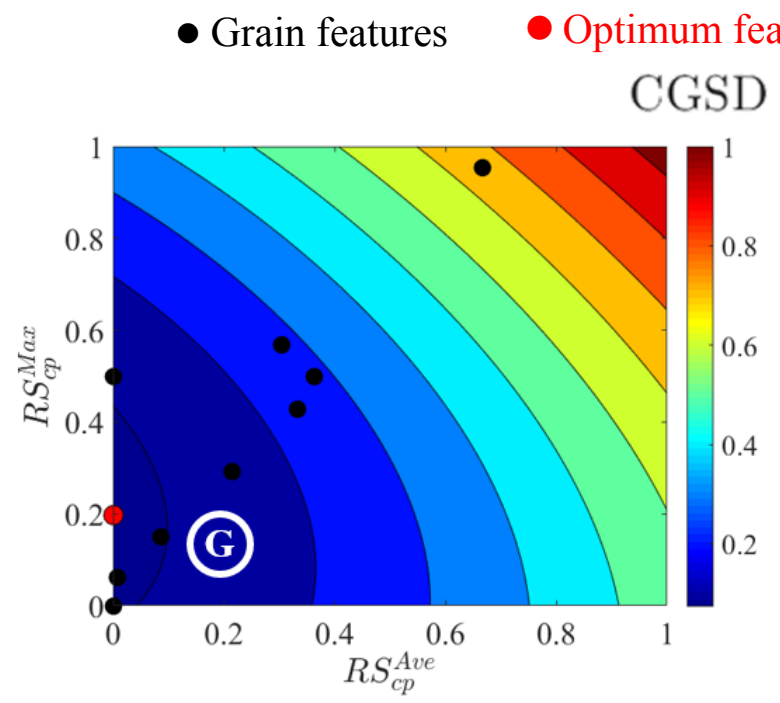

(a)

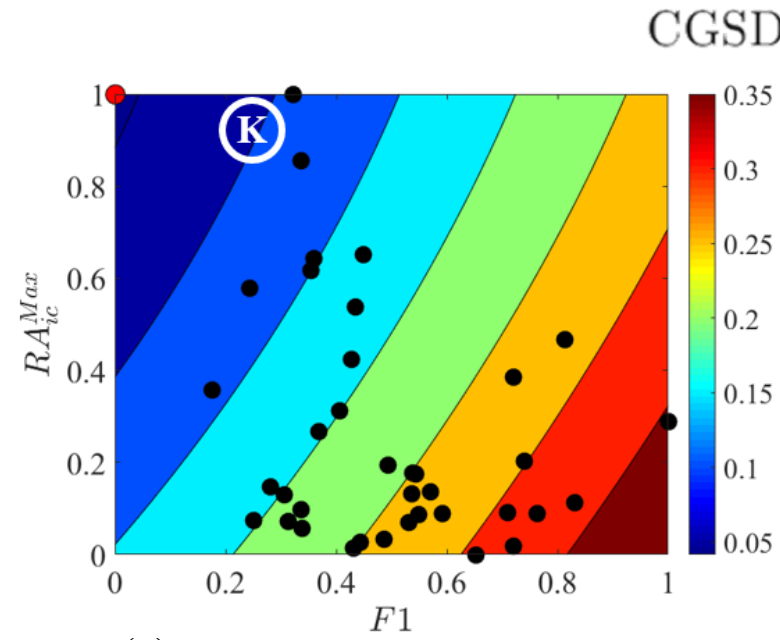

(c)

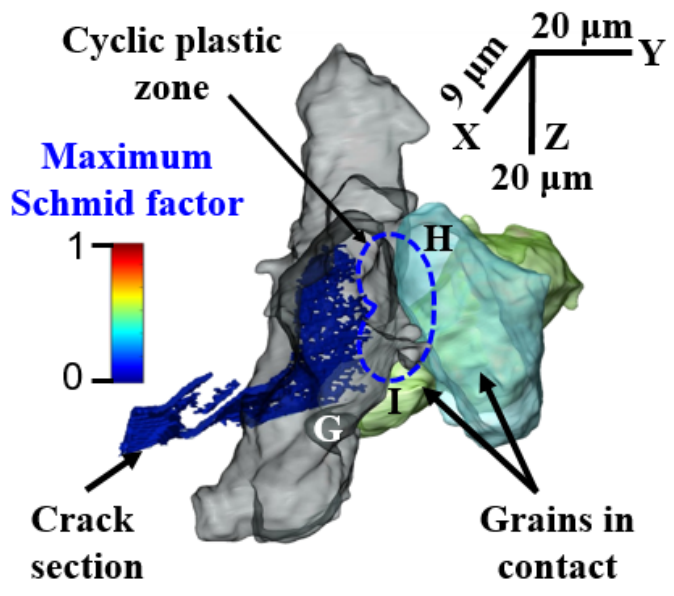

(b)

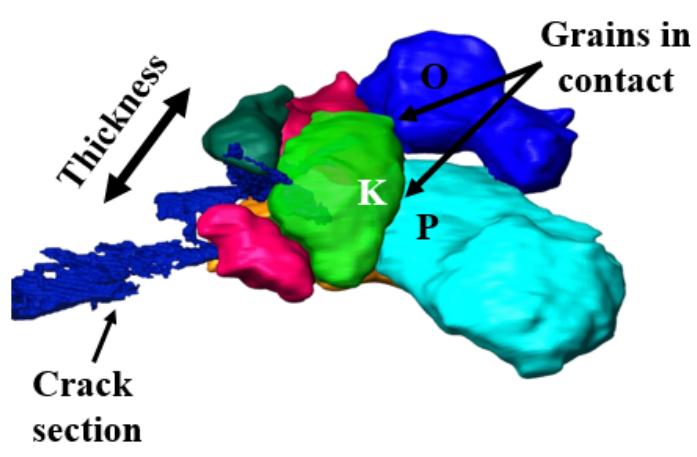

(d)

Figure 11. Contour projection of the 3D response surface curve for the two most contributing features to the crack growth rate standard deviation (CGSD). (a) Relationship between Schmid factors of grains in the cyclic plastic zone $\left(R S_{c p}{ }^{A v e}\right.$ and $R S_{c p}{ }^{M a x}$ ) with respect to CGSD in the first region. (b) Cracked grain G is surrounded by grains $\mathrm{H}$ and $\mathrm{I}$ in the cyclic plastic zone with lower average and maximum Schmid factors (low $R S_{c p}{ }^{A v e}$ and $R S_{c p}{ }^{M a x}$, respectively) has low CGSD. (c) Relationship between grain shape and its size compared to surrounding grains with respect to CGSD ( $F 1$ and $A_{i c}{ }^{M a x}$ ) for the longer short crack. (d) long cracked grain $\mathrm{K}$ along the thickness (low $F 1$ ) with lower surface area than the largest grain P in contact (high $A_{i c}{ }^{M a x}$ ) has low CGSD. 
Table 1. Description of geometrical and crystallographic features of grains.

\begin{tabular}{|c|c|c|}
\hline Category & Features & Description of the features \\
\hline Size of grain & $\begin{array}{l}A \\
V\end{array}$ & $\begin{array}{l}\text { Area } \\
\text { Volume }\end{array}$ \\
\hline$\left\lceil\begin{array}{l}\text { Loading } \\
\text { direction }\end{array}\right.$ & $\begin{array}{c}F 1=\Delta Y / \Delta X \\
F 2=\Delta Y / \Delta Z \\
F 3=\Delta X / \Delta Z \\
F 4=6 \sqrt{ } \pi(V / \sqrt{ } A) \\
M C \\
F 5=48\left(V / M^{3}\right) \\
F 6=4 \pi\left(S / M^{2}\right) \\
F 7=216\left(V^{2} / M^{3}\right) \\
F 8=288\left(V / M^{3}\right) \\
F 9=16\left(A / M^{2}\right) \\
S P \\
F 10=\pi(S P / 216 V)\end{array}$ & $\begin{array}{l}\text { Length to thickness ratio } \\
\text { Shape elongation in loading direction (YZ section) } \\
\text { Shape elongation perpendicular to loading direction (XZ section) } \\
\text { Shape deviation from a sphere } \\
\text { Integral of mean curvature } \\
\text { Volume to mean curvature of a non-spherical shape } \\
\text { Surface to mean curvature of a non-spherical shape } \\
\text { Shape deviation from a cube } \\
\text { Volume to mean curvature of a non-cubical shape } \\
\text { Surface to mean curvature of a non-cubical shape } \\
\text { Shortest continuous path in a grain } \\
\text { Elongation of grain considering the three dimension }\end{array}$ \\
\hline $\begin{array}{c}\text { Crystallograph } \\
\text {-ic features of } \\
\text { grain }\end{array}$ & $\begin{array}{c}O \\
S \\
B S \\
P S \\
P y S\end{array}$ & $\begin{array}{l}\text { Crystallographic orientation } \\
\text { Apparent maximum Schmid factor } \\
\text { Apparent basal Schmid factor } \\
\text { Apparent prismatic Schmid factor } \\
\text { Apparent pyramidal Schmid factor }\end{array}$ \\
\hline
\end{tabular}


Table 2. Microstructural features of surrounding grains as compared to the cracked grain.

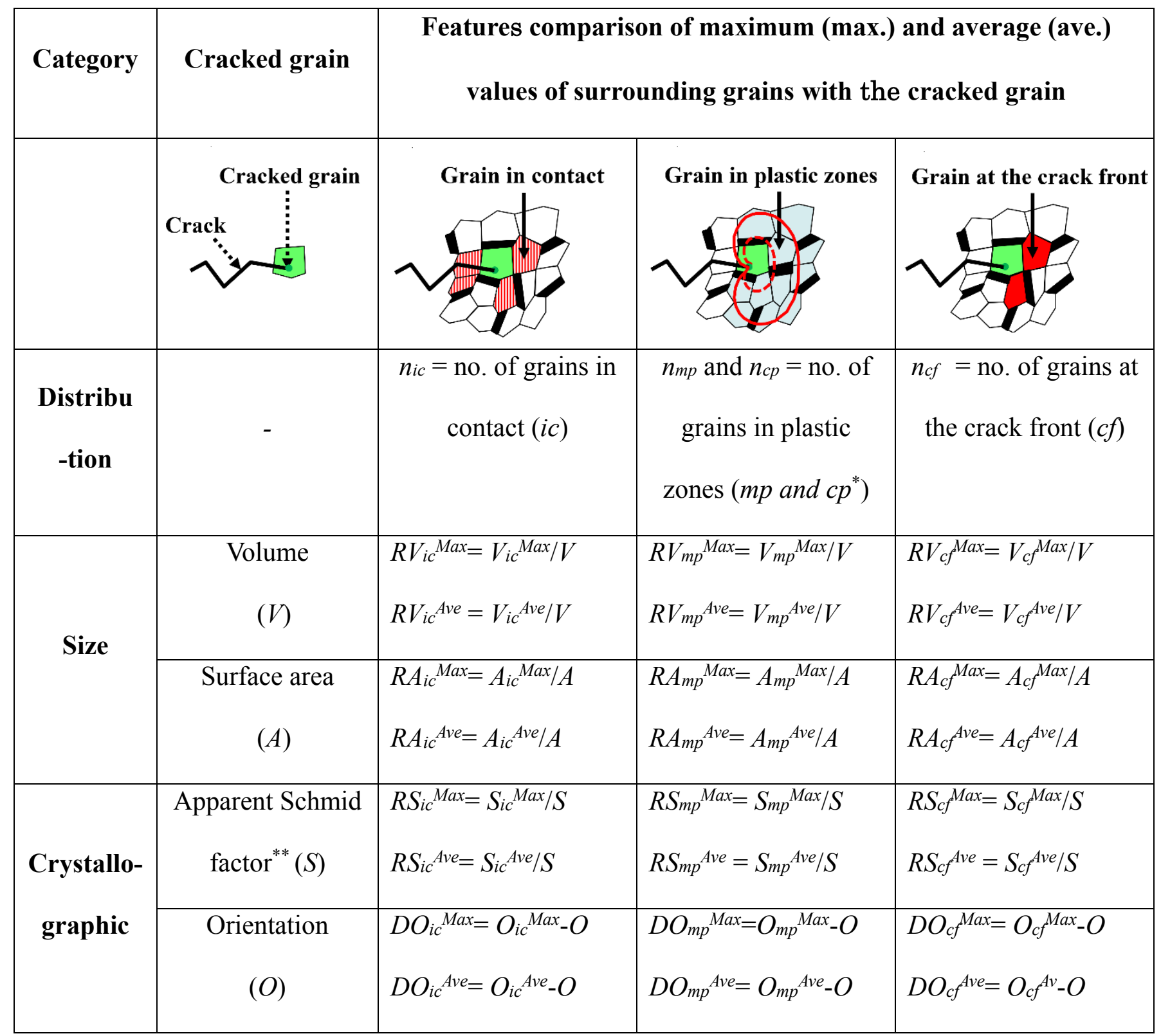

*Features for the cyclic plastic zone size have " $c p$ " subscript.

**Basal, prismatic and pyramidal Schmid factors are indexed using " $B S, P S$, and $P y S$ ", respectively. 